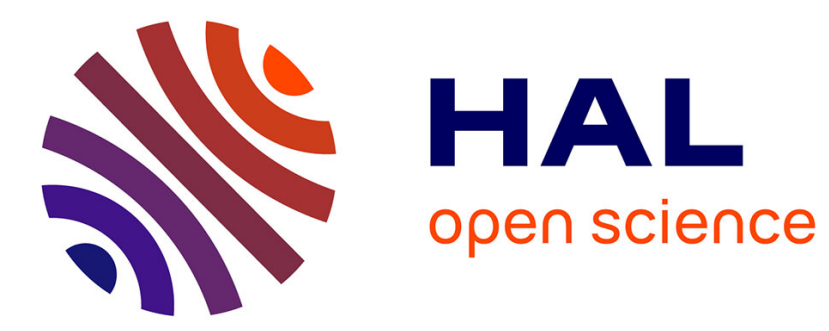

\title{
Constraints on upper mantle anisotropy surrounding the Cocos slab from $\mathrm{SK}(\mathrm{K}) \mathrm{S}$ splitting
}

\author{
David L. Abt, Karen M. Fischer, Geoffrey A. Abers, Marino Protti, Victor \\ González, Wilfried Strauch
}

\section{> To cite this version:}

David L. Abt, Karen M. Fischer, Geoffrey A. Abers, Marino Protti, Victor González, et al.. Constraints on upper mantle anisotropy surrounding the Cocos slab from SK(K)S splitting. Journal of Geophysical Research, 2010, 115, pp.06316. 10.1029/2009JB006710 . insu-00564751

HAL Id: insu-00564751

https://hal-insu.archives-ouvertes.fr/insu-00564751

Submitted on 4 Mar 2021

HAL is a multi-disciplinary open access archive for the deposit and dissemination of scientific research documents, whether they are published or not. The documents may come from teaching and research institutions in France or abroad, or from public or private research centers.
L'archive ouverte pluridisciplinaire HAL, est destinée au dépôt et à la diffusion de documents scientifiques de niveau recherche, publiés ou non, émanant des établissements d'enseignement et de recherche français ou étrangers, des laboratoires publics ou privés. 


\title{
Constraints on upper mantle anisotropy surrounding the Cocos slab from $S K(K) S$ splitting
}

\author{
David L. Abt, ${ }^{1,2}$ Karen M. Fischer, ${ }^{1}$ Geoffrey A. Abers, ${ }^{3}$ Marino Protti, ${ }^{4}$ Victor González, ${ }^{4}$ \\ and Wilfried Strauch ${ }^{5}$
}

Received 21 June 2009; revised 13 December 2009; accepted 21 January 2010; published 24 June 2010.

[1] SKS and SKKS splitting observations are used to constrain the pattern of mantle flow in the Central American subduction zone beneath Costa Rica and Nicaragua. After removing the effects of shallow wedge anisotropy on $S K(K) S$ waveforms, a best fitting model of anisotropy beneath the Cocos Plate and in the deeper mantle wedge is determined. Fast polarization directions and model symmetry axis orientations in both regions (as well as the shallow wedge) are dominated by roughly arc-parallel azimuths and, therefore, are not consistent with sublithospheric mantle flow entrained by the subducting Cocos Plate or simple two-dimensional corner flow in the wedge. In conjunction with geochemical data and local $S$ splitting tomography, the $S K(K) S$ splitting observations and anisotropy models are consistent with flow to the WNW within the mantle wedge on the Caribbean side of the Cocos Plate, possibly drawn through a slab window beneath Panama and southern Costa Rica. Anisotropy in the Pacific mantle beneath the Cocos Plate is also best explained by flow with a component that is roughly parallel to the strike of the slab, although the absolute direction of this flow is not uniquely constrained.

Citation: Abt, D. L., K. M. Fischer, G. A. Abers, M. Protti, V. González, and W. Strauch (2010), Constraints on upper mantle anisotropy surrounding the Cocos slab from $S K(K) S$ splitting, J. Geophys. Res., 115, B06316, doi:10.1029/2009JB006710.

\section{Introduction}

[2] The preferential alignment of olivine and orthopyroxene (opx) during deformation is often considered to be the dominant source of seismic anisotropy observed in the upper mantle, and shear wave splitting is one of the most widely used tools for investigating anisotropy in the mantle beneath subduction zones [e.g., Russo and Silver, 1994; Fouch and Fischer, 1996; Smith et al., 2001; Anderson et al., 2004; Levin et al., 2004; Long and van der Hilst, 2005; Pozgay et al., 2007; Greve et al., 2008; Long and Silver, 2008]. By assuming a relationship between the direction of deformation, or flow, and the lattice-preferred orientation (LPO) of these minerals, shear wave splitting parameters (i.e., fast polarization direction, $\phi$, and delay time, $d t$ ) can be used to infer the pattern of flow in the upper mantle [e.g., Silver and Chan, 1991; Mainprice and Silver, 1993; Savage, 1999; Long and Silver, 2008].

[3] Outside of the mantle wedge region in subduction zones, pressures and temperatures in the sublithospheric

\footnotetext{
${ }^{1}$ Department of Geological Sciences, Brown University, Providence, Rhode Island, USA.

${ }^{2}$ Now at ExxonMobil Exploration Company, Houston, Texas, USA.

${ }^{3}$ Lamont-Doherty Earth Observatory, Earth Institute at Columbia University, Palisades, New York, USA.

${ }^{4}$ Observatorio Vulcanológico y Sismológico de Costa Rica, Universidad Nacional, Heredia, Costa Rica.

${ }^{5}$ Instituto Nicaragüense de Estudios Territoriales, Managua, Nicaragua.

Copyright 2010 by the American Geophysical Union. 0148-0227/10/2009JB006710
}

upper mantle are likely to be such that dislocation creep in olivine is the dominant deformation mechanism, and under these conditions the [100] axis (or $a$ axis) of olivine is expected to align roughly parallel to the direction of flow during simple shear (e.g., rigid lithosphere driving deformation in the underlying asthenosphere with A-type slip [Zhang and Karato, 1995; Ismail and Mainprice, 1998; Mainprice et al., 2000]). Given these assumptions, the fast shear wave polarization direction in core phases (e.g., $P K(K)$ $S, S K(K) S)$ with near vertical incidence $\left(5^{\circ}-15^{\circ}\right)$ is expected to be parallel or subparallel to the mantle flow direction. In contrast, within the mantle wedge, the presence of additional water [Jung and Karato, 2001; Jung et al., 2006; Katayama and Karato, 2006; Jacobsen et al., 2008] and melt [Holtzman et al., 2003] and the likelihood of three-dimensional flow patterns [e.g., Kincaid and Griffiths, 2003; Funiciello et al., 2006; Kneller and van Keken, 2008] complicate the interpretation of shear wave splitting.

[4] Anisotropy within the mantle wedge beneath Costa Rica and Nicaragua has previously been investigated from shear wave splitting in local $S$ waves [Abt et al., 2009]. The highly variable local $S$ fast directions (Figure 1) made a direct interpretation in terms of flow difficult, and they were instead utilized in an inversion for anisotropic structure in the mantle wedge [Abt and Fischer, 2008; Abt et al., 2009]. The resulting model displayed a predominance of arc-parallel olivine $a$ axes throughout the mantle wedge and not only in the extreme wedge corner or beneath the volcanic arc where B-type fabric [Jung and Karato, 2001; Kneller et al., 2005] and melt bands [Holtzman et al., 2003], respec- 


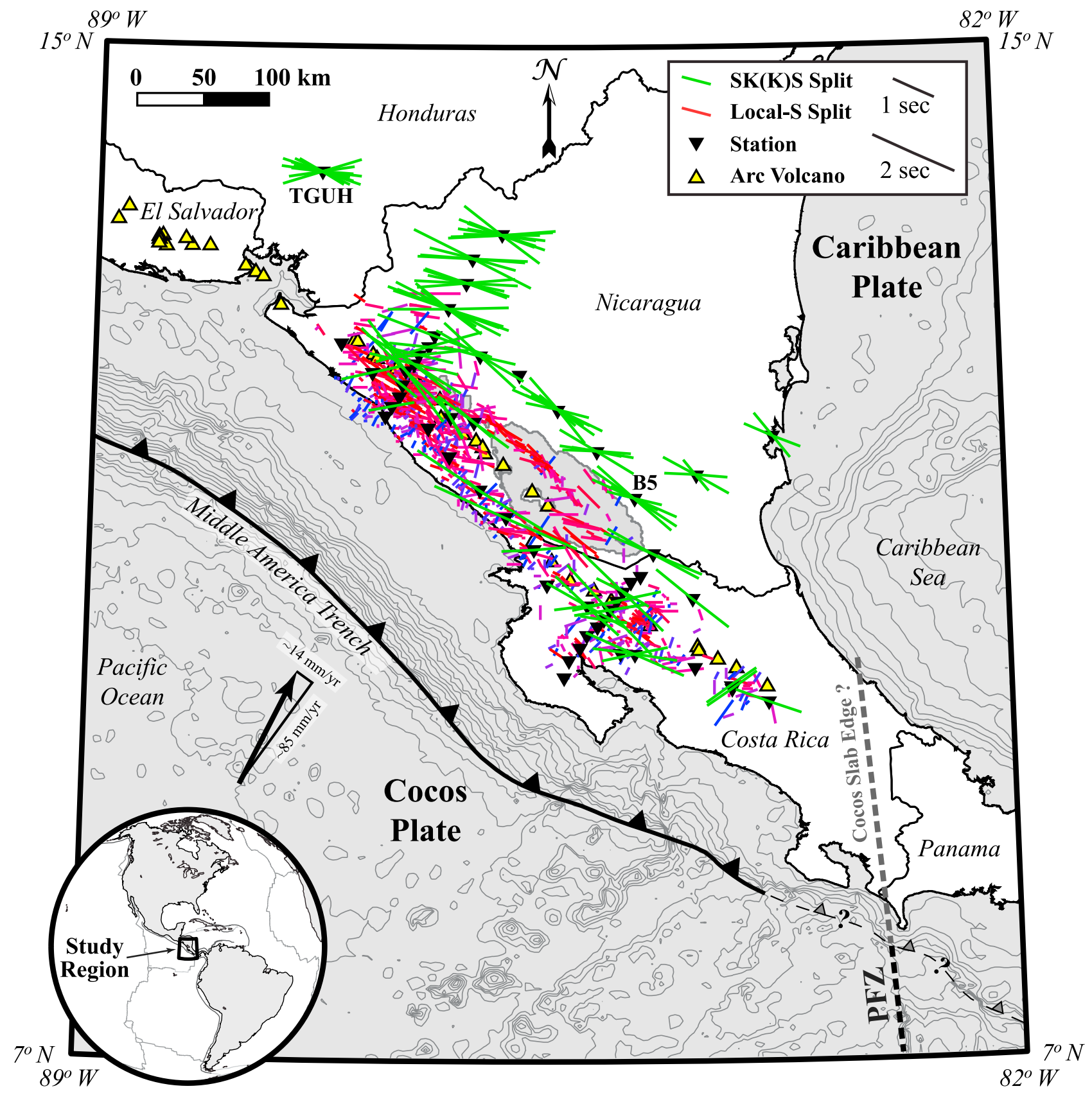

Figure 1. Map of $S K(K) S$ and local $S$ [Abt et al., 2009] splitting observations. $S K(K) S$ splitting vectors (green) are plotted at the station where they were measured, while local $S$ splits are plotted at raypath midpoints. Vector orientation is parallel to fast polarization direction and scaled to delay time (reference $d t$ of 1 and $2 \mathrm{~s}$ are shown in the legend). The color of the local $S$ vectors indicates azimuth as well and grades from red (arc-parallel) to blue (arc-normal). Black triangles are seismic stations, and yellow triangles are arc volcanoes; stations TGUH (splits not included in modeling) and B5 (example split shown in Figures 3 and 8) are identified. Cocos Plate motion relative to the Caribbean Plate (black arrow) is from DeMets [2001]. The Panama fracture zone (PFZ) and inferred edge of the Cocos slab [e.g., Protti et al., 1994; Herrstrom et al., 1995; Johnston and Thorkelson, 1997] are also shown with the dashed black and gray lines, respectively. The two major differences between the local $S$ and $S K(K) S$ splitting parameters are readily apparent here: (1) $S K(K) S$ fast directions are much more consistent (arc-parallel) than local $S$ fast directions, and (2) local $S$ delay times are generally much smaller than $S K(K) S$ delay times. 
tively, might affect fabric development and lead to a different relationship between flow direction and olivine $a$ axis orientation. Combined with $\mathrm{Pb}$ and $\mathrm{Nd}$ isotope data, the best interpretation of the local $S$ splitting and anisotropy model is that roughly horizontal along-arc flow to the northwest exists in the shallow $(<200 \mathrm{~km})$ mantle wedge [Hoernle et al., 2008; Abt et al., 2009].

[5] Along-arc flow in the mantle wedge is not consistent with the standard two-dimensional (2-D) corner flow expected to be present here in Central America given the relatively planar shape $\left(5^{\circ}-15^{\circ}\right.$ change in dip over $\sim 400 \mathrm{~km}$ along-strike [Protti et al., 1994; Husen et al., 2003; Syracuse and Abers, 2006]) and nearly orthogonal convergence $\left(7^{\circ}\right.$ in central Costa Rica, $17^{\circ}$ in Nicaragua [Barckhausen et al., 2001; DeMets, 2001]) of the Cocos Plate beneath the Caribbean Plate. A combination of trench motion, slab edge effects, and possible slab-wedge decoupling was suggested as a means of generating this arc-parallel flow [Hoernle et al., 2008; Abt et al., 2009]. However, due to the limited depth of local events $(<200 \mathrm{~km})$ and lateral extent of the seismic array used (Figure 1), a firstorder question left unanswered by the local $S$ splitting study is whether or not this counterintuitive pattern of arc-parallel anisotropy exists beyond the shallow mantle wedge. If it is confined to the shallow wedge and the mantle at greater depth possesses a more arc-normal orientation of anisotropy (i.e., that predicted for 2-D corner flow), then it is likely either that the deeper wedge becomes recoupled to the downgoing slab or that the source of shallow arc-parallel anisotropy is not simply mantle flow (e.g., B-type fabric, aligned melt, crustal anisotropy, or some combination of the these). On the other hand, pervasive arc-parallel anisotropy throughout the upper mantle would support models in which other drivers of flow (e.g., trench roll-back near a slab edge [Buttles and Olsen, 1998; Kincaid and Griffiths, 2003, 2004; Funiciello et al., 2006; Schellart et al., 2007; Honda, 2009] or global convection patterns [e.g., Conrad et al., 2007]) are locally more influential than downdip motion of the subducting Cocos Plate.

[6] Here we present $S K S$ and SKKS splitting measurements from Costa Rica, Nicaragua and Honduras that complement the local $S$ data and help constrain the orientation of flow both deeper in the back-arc wedge and beneath the Cocos Plate. In addition, after taking into account the local $S$ model of anisotropy [Abt et al., 2009], we calculate a best fitting crystallographic orientation for both the subslab and deeper wedge and find that each region likely contains anisotropy characterized by shallowly dipping, roughly arc-parallel olivine $a$ axes (from here on, referred to as the symmetry axis, given that we will assume hexagonal crystallographic symmetry). This result suggests arc-parallel flow is indeed the most probable source for anisotropy in the shallow wedge imaged by local $S$ splitting tomography, as well as in the deeper wedge and subslab mantle.

\section{2. $S K(K) S$ Splitting}

\subsection{Calculation of Splitting Parameters}

[7] Shear wave splitting parameters $(\phi, d t)$ are calculated here from the SV and SH components of motion using an eigenvalue minimization technique [Silver and Chan, 1991].
A zero-phase, band-pass filter of $0.05-0.2 \mathrm{~Hz}$ (periods of 5 $20 \mathrm{~s}$ ) is first applied to the raw waveforms, the Z-N-E components are then rotated into Z-R-T, and finally, the waveforms are transformed into the $P-\mathrm{SV}-\mathrm{SH}$ coordinate system by correcting for the effects of the free surface [Kennett, 1991] assuming a surface $V_{P}$ and $V_{S}$ of 5.9 and $3.41 \mathrm{~km} / \mathrm{s}$, respectively. Raypaths are traced through the 1-D reference Earth model AK135 [Kennett et al., 1995]. While splitting measurements are typically made on the horizontal components of motion (i.e., N-E or R-T [e.g., Silver and Chan, 1991; Fouch and Fischer, 1996; Savage, 1999]), with fast polarization direction measured in degrees east of north, fast directions here are measured clockwise from SV in the SV-SH plane (Figure 2). Although the difference between the splitting parameters measured in these two coordinate systems is generally minimal (Figure 3 ) given the subvertical incidence angle of most $S K(K) S$ waves, we choose to use the splitting measurements made from the SV-SH components and not those from the projected N-E, or R-T, components. The window used for analysis is manually chosen and typically includes $20-30 \mathrm{~s}$ prior to and at least $1.5-2$ periods after the phase arrival. Error bars $\left(\sigma_{\phi, d t}\right)$ are the standard splitting parameter errors given by the maximum distance from the best fitting $\phi$ and $d t$ to the $95 \%$ confidence contour of the $\lambda_{2}$ surface (e.g., Figures 3c and 3f) [also see Abt and Fischer, 2008].

\subsection{Observations}

[8] Our data were recorded by the Tomography Under Costa Rica and Nicaragua (TUCAN) seismic array, a temporary network of 48 broadband seismic stations deployed from July 2004 to March 2006, as well as four permanent stations: BOA (INETER and GEOFON, Program of GFZ Potsdam), HDC (OVSICORI and GEOSCOPE, Institut de Physique du Globe), JTS (OVSICORI and IRIS, Scripps Institute of Oceanography), and TGUH (Caribbean Network, USGS). More than 1900 waveforms from events with magnitude $>=6.5$ and epicentral distance between $85^{\circ}$ and $170^{\circ}$ were visually inspected for clear $S K S$ and $S K K S$ arrivals, and of these, more than 900 were analyzed with the method described in section 2.1, resulting in 103 "highquality" splitting measurements (Figure 1 and Table 1). We use four basic criteria for assessing the quality of splitting measurements (as in the work by Abt et al. [2009]); a "highquality" (i.e., interpretable) measurement will (1) possess a clear phase arrival with a high signal-to-noise ratio, (2) display elliptical or circular particle motion, (3) have a single, elliptical $95 \%$ contour, and (4) return roughly linear particle motion with dominantly SV energy when the waveforms are corrected for the best fitting pair of splitting parameters. Although we do not use strict limits on the size of the $95 \%$ confidence region, only 3 of the 103 splits presented here have a fast direction error of $>30^{\circ}$ and 19 have a delay time error $>0.6 \mathrm{~s}$ (Table 1).

[9] In contrast to the relatively complicated pattern of local $S$ fast directions [Abt et al., 2009], the teleseismic $S K$ $(K) S$ fast directions observed here are more consistently arcparallel and subarc-parallel (Figures 1, 4, and 5). $S K(K) S$ delay times $(1-3 \mathrm{~s})$ are also generally much larger than those of local $S(0.1-0.6 \mathrm{~s})$, indicating a significant amount of anisotropy outside the shallow wedge and upper plate volumes sampled by local $S$ waves. The azimuthal distribution 


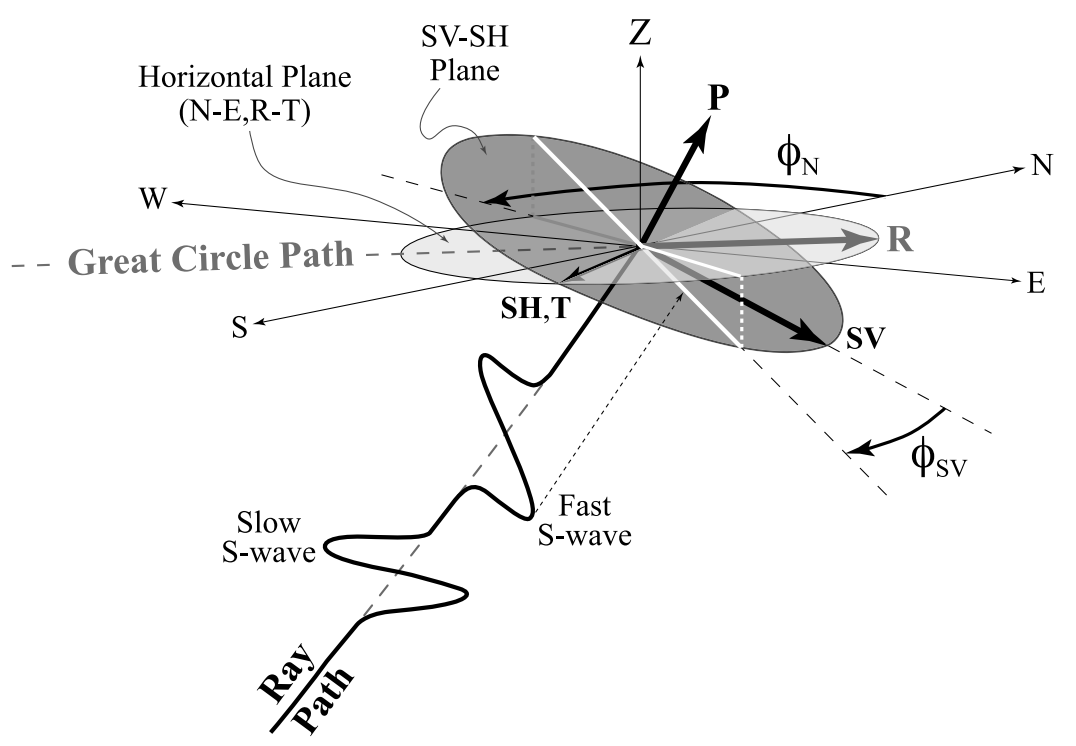

Figure 2. Schematic illustration of the relationship between the Z-R-T and $P$-SV-SH coordinate systems. The free surface transform [Kennett, 1991] assuming $V_{P}=5.9 \mathrm{~km} / \mathrm{s}$ and $V_{S}=3.41 \mathrm{~km} / \mathrm{s}$ is used to obtain the $P$-SV-SH components. We measure fast polarization direction clockwise from SV in the SV-SH plane (the white line represents the splitting vector). Figure 3 shows an example of the (minor) differences in waveforms and associated splitting parameters between the two coordinate systems.
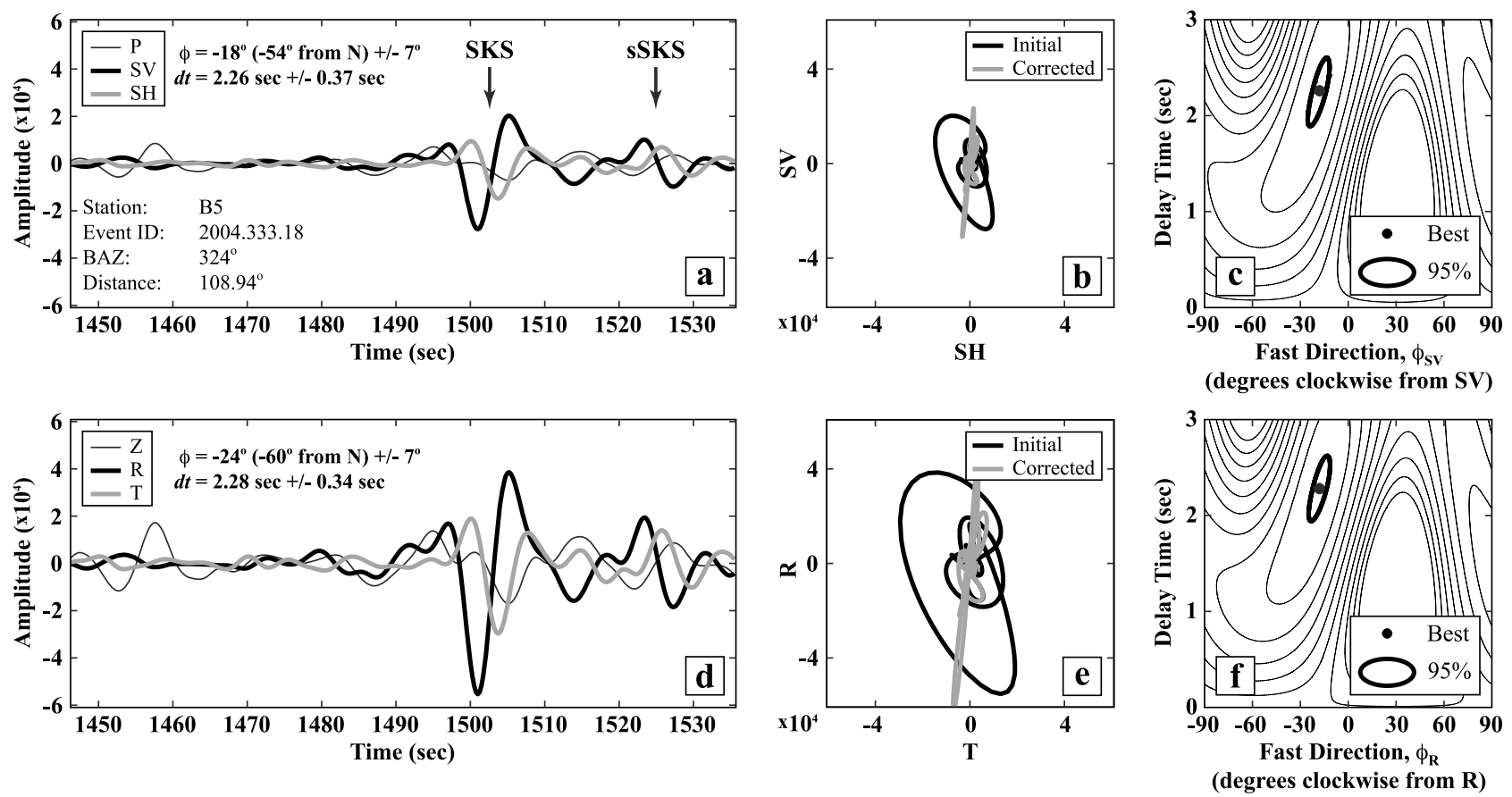

Figure 3. Example splitting parameter calculation in the (a-c) SV-SH and $(\mathrm{d}-\mathrm{f}) \mathrm{R}-\mathrm{T}$ planes. The splitting parameters shown in all other figures and referred to throughout the text are those measured in the SV-SH plane. The windowed waveforms used in the calculation are illustrated in Figures $3 \mathrm{a}$ and $3 \mathrm{~d}$, particle motions are shown in Figures $3 \mathrm{~b}$ and $3 \mathrm{e}$, and the $\lambda_{2}$ (see section 2.1) values are contoured around the best fitting splitting parameter pair (black dot) in Figures $3 \mathrm{c}$ and $3 \mathrm{f}$, with the $95 \%$ confidence region shown with the thick black line. The event for this particular example was at a depth of $39 \mathrm{~km}$ and produced a very clear $S S K S$ arrival, which was included in the analysis window together with the $S K S$ phase. This secondary phase can be seen on both the waveforms and in the initial particle motion plots (black line in Figures $3 \mathrm{~b}$ and 3c), with its polarity reversed relative to that of the $S K S$ phase. As expected and demonstrated by the linear corrected particle motion (gray line in Figures $3 \mathrm{~b}$ and $3 \mathrm{c}$ ), the splitting of both phases is well characterized by the same pair of $\phi$ and $d t$. 
Table 1. Observed $S K(K) S$ Splitting Parameters ${ }^{\text {a }}$

\begin{tabular}{|c|c|c|c|c|c|c|c|c|c|}
\hline Event & Event ID (YEAR.JDY.HH) & Station & BAZ (deg) & DIST (deg) & Phase & $\phi(\operatorname{deg})$ & $\sigma_{\phi}(\operatorname{deg})$ & $\mathrm{dt}(\mathrm{deg})$ & $\sigma_{\mathrm{dt}}(\mathrm{deg})$ \\
\hline 1 & 2004.249 .10 & TISM & 319 & 119 & $S K K S$ & -54 & 26 & 1.92 & 0.63 \\
\hline 2 & 2004.250 .23 & B3 & 320 & 119 & $S K K S$ & -66 & 14 & 2.21 & 0.53 \\
\hline 3 & 2004.250 .23 & N12 & 320 & 118 & $S K K S$ & -64 & 20 & 2.92 & 0.47 \\
\hline 4 & 2004.250 .23 & N13 & 320 & 118 & $S K K S$ & -89 & 27 & 1.71 & 0.48 \\
\hline 5 & 2004.250 .23 & N9 & 319 & 118 & $S K K S$ & -70 & 20 & 2.71 & 0.39 \\
\hline 6 & 2004.282 .08 & B3 & 263 & 114 & $S K S$ & -49 & 26 & 1.07 & 0.30 \\
\hline 7 & 2004.282 .08 & B4 & 263 & 114 & $S K S$ & -87 & 20 & 1.50 & 0.42 \\
\hline 8 & 2004.282 .08 & $\mathrm{C} 12$ & 263 & 115 & $S K S$ & -38 & 21 & 0.92 & 0.23 \\
\hline 9 & 2004.282 .08 & $\mathrm{C} 13$ & 263 & 116 & $S K S$ & -38 & 26 & 1.28 & 0.25 \\
\hline 10 & 2004.316 .17 & B3 & 263 & 114 & $S K S$ & -58 & 18 & 1.34 & 0.27 \\
\hline 11 & 2004.322 .21 & B3 & 251 & 97 & $S K S$ & -39 & 20 & 1.96 & 0.65 \\
\hline 12 & 2004.322 .21 & $\mathrm{C} 13$ & 251 & 99 & $S K S$ & -67 & 26 & 1.34 & 0.44 \\
\hline 13 & 2004.322 .21 & N10 & 251 & 97 & $S K S$ & -67 & 21 & 1.33 & 0.40 \\
\hline 14 & 2004.322 .21 & N11 & 251 & 97 & $S K S$ & -71 & 16 & 1.92 & 0.32 \\
\hline 15 & 2004.322 .21 & RITO & 251 & 97 & $S K S$ & -61 & 24 & 1.32 & 0.30 \\
\hline 16 & 2004.322 .21 & TESU & 251 & 97 & $S K S$ & 82 & 31 & 1.57 & 0.78 \\
\hline 17 & 2004.333 .18 & B1 & 323 & 107 & $S K S$ & -48 & 12 & 2.17 & 0.30 \\
\hline 18 & 2004.333 .18 & B3 & 324 & 108 & $S K S$ & -56 & 7 & 1.97 & 0.41 \\
\hline 19 & 2004.333 .18 & B4 & 324 & 108 & $S K S$ & -57 & 7 & 1.91 & 0.45 \\
\hline 20 & 2004.333 .18 & B4 & 324 & 108 & $S K K S$ & -79 & 28 & 1.63 & 0.65 \\
\hline 21 & 2004.333 .18 & B5 & 324 & 109 & $S K S$ & -54 & 7 & 2.26 & 0.37 \\
\hline 22 & 2004.333 .18 & B5 & 324 & 109 & $S K K S$ & -65 & 20 & 2.04 & 0.61 \\
\hline 23 & 2004.333 .18 & $\mathrm{C} 12$ & 324 & 109 & $S K S$ & -60 & 31 & 1.67 & 0.83 \\
\hline 24 & 2004.333 .18 & COLI & 323 & 109 & $S K S$ & -46 & 19 & 1.95 & 0.73 \\
\hline 25 & 2004.333 .18 & COVE & 324 & 110 & $S K S$ & -49 & 14 & 2.08 & 0.76 \\
\hline 26 & 2004.333 .18 & LSOL & 323 & 110 & $S K K S$ & -65 & 15 & 2.34 & 0.53 \\
\hline 27 & 2004.333 .18 & N10 & 323 & 107 & $S K S$ & -70 & 9 & 2.41 & 0.21 \\
\hline 28 & 2004.333 .18 & N10 & 323 & 107 & $S K K S$ & 89 & 19 & 2.67 & 0.69 \\
\hline 29 & 2004.333 .18 & N11 & 323 & 107 & $S K S$ & -74 & 11 & 2.00 & 0.20 \\
\hline 30 & 2004.333 .18 & N12 & 323 & 107 & $S K S$ & -76 & 15 & 1.97 & 0.36 \\
\hline 31 & 2004.333 .18 & N12 & 323 & 107 & $S K K S$ & -86 & 11 & 2.35 & 0.25 \\
\hline 32 & 2004.333 .18 & N13 & 324 & 107 & $S K S$ & -69 & 9 & 1.58 & 0.12 \\
\hline 33 & 2004.333 .18 & N13 & 324 & 107 & $S K K S$ & 87 & 11 & 2.38 & 0.25 \\
\hline 34 & 2004.333 .18 & N5 & 323 & 107 & $S K S$ & -47 & 14 & 2.77 & 0.78 \\
\hline 35 & 2004.333 .18 & N6 & 323 & 107 & $S K S$ & -58 & 14 & 2.49 & 0.38 \\
\hline 36 & 2004.333 .18 & N7 & 323 & 107 & $S K S$ & 83 & 14 & 1.76 & 0.38 \\
\hline 37 & 2004.333 .18 & N8 & 323 & 107 & $S K S$ & -85 & 16 & 1.76 & 0.32 \\
\hline 38 & 2004.333 .18 & RITO & 324 & 109 & $S K S$ & -45 & 11 & 2.53 & 0.80 \\
\hline 39 & 2004.333 .18 & TABL & 324 & 109 & $S K K S$ & -60 & 21 & 2.29 & 0.73 \\
\hline 40 & 2004.333 .18 & TENO & 323 & 110 & $S K S$ & 77 & 20 & 2.01 & 0.51 \\
\hline 41 & 2004.333 .18 & TESU & 323 & 110 & $S K S$ & -42 & 10 & 2.79 & 0.49 \\
\hline 42 & 2004.341 .14 & B1 & 323 & 107 & $S K S$ & -60 & 10 & 2.26 & 0.27 \\
\hline 43 & 2004.341 .14 & B3 & 323 & 108 & $S K S$ & -65 & 17 & 1.58 & 0.48 \\
\hline 44 & 2004.341 .14 & B5 & 324 & 109 & $S K S$ & -49 & 9 & 2.20 & 0.48 \\
\hline 45 & 2004.341 .14 & $\mathrm{C} 12$ & 324 & 109 & $S K S$ & -85 & 24 & 1.40 & 0.46 \\
\hline 46 & 2004.341 .14 & COLI & 323 & 109 & $S K S$ & -60 & 18 & 2.04 & 0.50 \\
\hline 47 & 2004.341 .14 & LSOL & 323 & 110 & $S K K S$ & -81 & 17 & 1.84 & 0.37 \\
\hline 48 & 2004.341 .14 & N10 & 323 & 107 & $S K S$ & -70 & 8 & 2.30 & 0.19 \\
\hline 49 & 2004.341 .14 & N10 & 323 & 107 & $S K K S$ & -72 & 13 & 2.59 & 0.39 \\
\hline 50 & 2004.341 .14 & N11 & 323 & 107 & $S K S$ & -87 & 11 & 2.32 & 0.24 \\
\hline 51 & 2004.341 .14 & N13 & 323 & 107 & $S K S$ & -72 & 12 & 1.62 & 0.19 \\
\hline 52 & 2004.341 .14 & N13 & 323 & 107 & $S K K S$ & 87 & 14 & 2.29 & 0.34 \\
\hline 53 & 2004.341 .14 & N5 & 323 & 107 & $S K S$ & -37 & 14 & 2.86 & 0.92 \\
\hline 54 & 2004.341 .14 & N6 & 323 & 107 & $S K S$ & -51 & 14 & 2.13 & 0.56 \\
\hline 55 & 2004.341 .14 & N7 & 323 & 107 & $S K S$ & -77 & 27 & 1.55 & 0.44 \\
\hline 56 & 2004.341 .14 & N8 & 323 & 107 & $S K S$ & 74 & 12 & 2.45 & 0.50 \\
\hline 57 & 2004.341 .14 & TABL & 324 & 109 & SKKS & -66 & 17 & 2.36 & 0.61 \\
\hline 58 & 2005.036 .12 & F5 & 298 & 146 & $S K K S$ & -58 & 20 & 3.29 & 0.85 \\
\hline 59 & 2005.036 .12 & F6 & 298 & 147 & $S K K S$ & -66 & 9 & 3.46 & 0.70 \\
\hline 60 & 2005.036 .12 & HDC & 298 & 149 & $S K K S$ & 55 & 28 & 1.35 & 0.61 \\
\hline 61 & 2005.036 .12 & HDC5 & 298 & 149 & $S K K S$ & 54 & 28 & 1.36 & 0.64 \\
\hline 62 & 2005.036 .12 & IRZU & 298 & 149 & $S K K S$ & -69 & 17 & 1.51 & 0.34 \\
\hline 63 & 2005.100 .10 & B3 & 334 & 168 & $S K K S$ & -63 & 30 & 1.09 & 0.53 \\
\hline 64 & 2005.100 .10 & B4 & 335 & 169 & $S K K S$ & -78 & 37 & 1.14 & 0.54 \\
\hline 65 & 2005.100 .10 & B5 & 336 & 169 & $S K K S$ & -74 & 26 & 1.23 & 0.46 \\
\hline 66 & 2005.100 .10 & N13 & 335 & 167 & $S K K S$ & -80 & 9 & 1.55 & 0.41 \\
\hline 67 & 2005.134 .05 & N10 & 341 & 166 & $S K K S$ & -57 & 27 & 1.47 & 0.35 \\
\hline 68 & 2005.323 .14 & B5 & 353 & 166 & $S K K S$ & -76 & 26 & 1.26 & 0.37 \\
\hline 69 & 2005.323 .14 & N10 & 348 & 165 & $S K K S$ & -53 & 18 & 1.86 & 0.48 \\
\hline 70 & 2005.336 .13 & N10 & 321 & 112 & $S K S$ & -70 & 14 & 2.88 & 0.46 \\
\hline 71 & 2005.336 .13 & N10 & 321 & 112 & $S K K S$ & -63 & 15 & 2.64 & 0.45 \\
\hline 72 & 2005.336 .13 & N11 & 321 & 112 & $S K K S$ & 85 & 15 & 2.18 & 0.48 \\
\hline
\end{tabular}


Table 1. (continued)

\begin{tabular}{|c|c|c|c|c|c|c|c|c|c|}
\hline Event & Event ID (YEAR.JDY.HH) & Station & BAZ (deg) & DIST (deg) & Phase & $\phi(\operatorname{deg})$ & $\sigma_{\phi}(\operatorname{deg})$ & dt (deg) & $\sigma_{\mathrm{dt}}(\mathrm{deg})$ \\
\hline 73 & 2005.336 .13 & N13 & 321 & 112 & $S K S$ & -53 & 16 & 2.14 & 0.52 \\
\hline 74 & 2005.336 .13 & N13 & 321 & 112 & $S K K S$ & -71 & 19 & 2.02 & 0.39 \\
\hline 75 & 2005.339 .12 & N6 & 91 & 117 & $S K S$ & -77 & 12 & 2.00 & 0.54 \\
\hline 76 & 2006.002 .22 & B1 & 251 & 96 & $S K S$ & -76 & 11 & 1.63 & 0.19 \\
\hline 77 & 2006.002 .22 & B3 & 251 & 97 & $S K S$ & -76 & 13 & 1.41 & 0.14 \\
\hline 78 & 2006.002 .22 & B5 & 251 & 97 & $S K S$ & -60 & 13 & 1.16 & 0.45 \\
\hline 79 & 2006.002 .22 & COLI & 251 & 96 & $S K S$ & 84 & 9 & 1.44 & 0.26 \\
\hline 80 & 2006.002 .22 & F2 & 251 & 95 & $S K S$ & 78 & 13 & 1.39 & 0.50 \\
\hline 81 & 2006.002 .22 & F5 & 251 & 96 & $S K S$ & -53 & 26 & 0.78 & 0.43 \\
\hline 82 & 2006.002 .22 & LSOL & 251 & 97 & $S K S$ & 79 & 7 & 1.47 & 0.61 \\
\hline 83 & 2006.002 .22 & MGA1 & 251 & 96 & $S K S$ & -30 & 12 & 1.10 & 0.51 \\
\hline 84 & 2006.002 .22 & MGA2 & 251 & 96 & $S K S$ & -31 & 13 & 1.09 & 0.51 \\
\hline 85 & 2006.002 .22 & N11 & 251 & 96 & $S K S$ & -79 & 9 & 1.72 & 0.22 \\
\hline 86 & 2006.002 .22 & N12 & 251 & 96 & $S K S$ & -87 & 7 & 2.45 & 0.25 \\
\hline 87 & 2006.002 .22 & N13 & 251 & 97 & $S K S$ & -83 & 12 & 1.97 & 0.52 \\
\hline 88 & 2006.002 .22 & $\mathrm{~N} 2$ & 251 & 96 & $S K S$ & 79 & 22 & 1.02 & 0.50 \\
\hline 89 & 2006.002 .22 & N4 & 251 & 96 & $S K S$ & -51 & 14 & 0.86 & 0.33 \\
\hline 90 & 2006.002 .22 & PALM & 251 & 96 & $S K S$ & -81 & 31 & 1.03 & 0.50 \\
\hline 91 & 2006.002 .22 & SONZ & 251 & 96 & $S K S$ & 87 & 6 & 1.42 & 0.22 \\
\hline 92 & 2006.002 .22 & TESU & 251 & 97 & $S K S$ & 82 & 8 & 1.50 & 0.33 \\
\hline 93 & 2006.002 .22 & TISM & 251 & 96 & $S K S$ & -49 & 10 & 1.02 & 0.35 \\
\hline 94 & 2007.271 .13 & TGUH & 119 & 306 & $S K S$ & -83 & 10 & 2.03 & 0.42 \\
\hline 95 & 2007.271 .13 & TGUH & 119 & 306 & SKKS & 82 & 27 & 1.67 & 0.48 \\
\hline 96 & 2007.354 .07 & TGUH & 102 & 232 & $S K S$ & -80 & 20 & 1.44 & 0.29 \\
\hline 97 & 2007.354 .07 & TGUH & 102 & 232 & $S K K S$ & 72 & 14 & 2.07 & 0.41 \\
\hline 98 & 2008.045 .10 & TGUH & 96 & 50 & $S K S$ & -61 & 26 & 1.29 & 0.26 \\
\hline 99 & 2008.063 .09 & TGUH & 99 & 323 & $S K S$ & -85 & 13 & 1.58 & 0.21 \\
\hline 100 & 2008.197 .03 & TGUH & 101 & 48 & $S K S$ & -81 & 6 & 1.4 & 0.09 \\
\hline 101 & 2008.197 .03 & TGUH & 101 & 48 & $S K K S$ & -66 & 14 & 1.54 & 0.24 \\
\hline 102 & 2008.201.02 & TGUH & 111 & 320 & $S K K S$ & -74 & 17 & 1.63 & 0.35 \\
\hline 103 & 2008.205 .15 & TGUH & 110 & 322 & $S K K S$ & -73 & 15 & 2.05 & 0.34 \\
\hline
\end{tabular}

${ }^{a}$ YEAR.JDY.HH, year, Julian day of year, hours local time; BAZ, back azimuth; DIST, distance. Event information for each split can be obtained by associating Event IDs given here with the year, Julian day, and hours in Table 2. Fast directions are measured east of north. Errors $\left(\sigma_{\phi}\right.$ and $\left.\sigma_{d t}\right)$ are measured on the $95 \%$ confidence contour of the $\lambda 2$ surface (e.g., Figure $3 \mathrm{c}$, section 2.1 ).

of events from the splitting measurements is neither uniform nor complete (Figure 5). In addition, one set of raypaths primarily sample the mantle beneath the subducting Cocos Plate (i.e., Pacific) and another set primarily samples the wedge-side (i.e., Caribbean) mantle (Figures 5 and 6 and Table 2); note that here and in the modeling (section 3 ), we do not include the raypaths and splits to station TGUH because they fall further outside the local $S$ model space. We find a relatively small difference in splitting parameters (on average, $5^{\circ}$ in $\phi$ and $0.30 \mathrm{~s}$, or $15 \%$, in $d t$ ) between Caribbean and Pacific rays (Figure 7); the mean $\phi$ and $d t$ of the 66 (27) splits from the Caribbean (Pacific) side are $-69^{\circ}\left(-74^{\circ}\right)$ and $1.95 \mathrm{~s}(1.65 \mathrm{~s})$.

[10] Qualitatively, the consistency in $S K(K) S$ fast directions suggests a similar orientation of anisotropy in both Pacific mantle beneath the Cocos Plate and Caribbean mantle on the wedge side of the Cocos Plate (e.g., approximately arc-parallel symmetry axes). The slight difference in average delay time between waves sampling the two mantle regions could be attributed to differing path lengths through a shallow mantle wedge that possesses a higher degree of anisotropy than the subslab or deeper $(>200 \mathrm{~km})$ wedge mantle; rays on the Caribbean side generally have a greater fraction of their path within the shallow wedge (Figure 6). On the other hand, the difference in $d t$ could also indicate a difference in the strength and/or orientation of anisotropy outside the mantle wedge between the two regions. For example, the predicted strength of anisotropy in a $70 \%$ olivine, $30 \%$ orthopyroxene aggregate (assuming hexagonal symmetry) for subvertical $\left(10^{\circ}\right.$ incidence angle) ray propagation decreases from $\sim 8.5 \%$ to $\sim 1 \%$ as the symmetry axis rotates from horizontal to vertical (Figure S1 in the auxiliary material). ${ }^{1}$ To more quantitatively characterize anisotropy, in section 3, we use the local $S$ splitting tomography model to remove the effects of anisotropy in the shallow wedge on $S K(K) S$ waveforms and calculate best fitting models of anisotropy in these two mantle regions.

[11] Several studies have documented differences in splitting between $S K S$ and $S K K S$ phases and have attributed them to anisotropy in the deep lower mantle, the coremantle boundary region in particular [Niu and Perez, 2004; Restivo and Helffrich, 2006; Long, 2009]. In our data set, differences between $S K S$ and $S K K S$ splitting parameters for common source receiver pairs are very slight. Of the nine cases for which well-resolved $S K S$ and $S K K S$ splitting parameters were obtained for the same source and receiver, five agreed within the confidence limits of the measurements. In three of the other four cases, differences in fast direction exceeded the uncertainties by only $5^{\circ}$ or less, and in two cases differences in splitting time exceeded uncertainties by $0.43 \mathrm{~s}$ or less. For events at back azimuths of $321^{\circ}-324^{\circ}$ and distances of $107^{\circ}-112^{\circ}, S K K S$ fast directions tend to be rotated slightly counterclockwise from $S K S$ fast

\footnotetext{
${ }^{1}$ Auxiliary materials are available in the HTML. doi:10.1029/ 2009JB006710.
} 


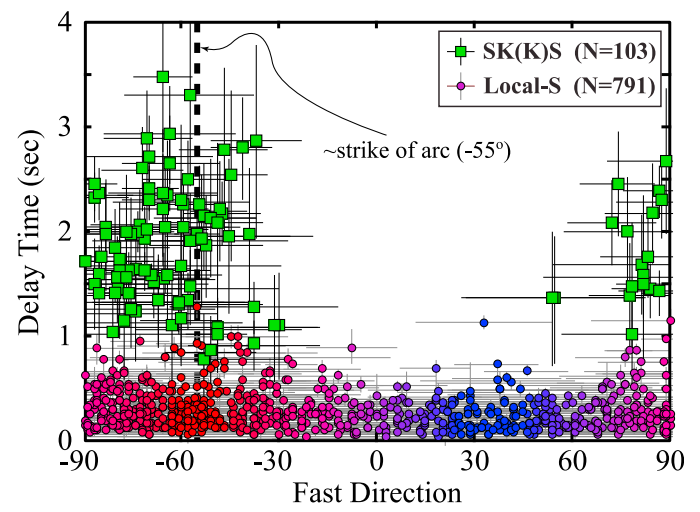

Figure 4. Comparison of $S K(K) S$ and local $S$ splitting parameters. $S K(K) S$ splits are shown in green, and local $S$ splits grade from red (arc-parallel $\phi$ ) to blue (arc-normal $\phi$ ). Error bars on both are the standard splitting errors (e.g., measured from the $95 \%$ confidence contour in Figure $3 \mathrm{c}$; see section 2.1). The approximate strike of the volcanic arc $\left(\mathrm{N} 55^{\circ} \mathrm{W}\right)$ is shown with the black dashed line. As can also be seen in map view (Figure 1), $S K(K) S$ fast directions do not show the same variability as local $S$ fast directions, and delay times for $S K(K) S$ are much larger.

directions. However, as described above, this trend is not well resolved at $95 \%$ confidence. Therefore, we jointly model the $S K S$ and $S K K S$ splitting in terms of upper mantle anisotropy beneath the TUCAN stations.

\section{Subslab and Deep Back-Arc Anisotropy}

\subsection{Incorporation of Local $S$ Splitting Tomography Model}

[12] Given the model of anisotropy (i.e., crystallographic orientation and strength of anisotropy) in the shallow $(<200 \mathrm{~km})$ mantle wedge determined from local $S$ splitting tomography [Abt et al., 2009], we can correct for the predicted birefringence that would be accrued by $S K(K) S$ phases during passage through this region. To accomplish this, the observed $S K(K) S$ waveforms from all stations (except TGUH, which lies outside the local $S$ model region) were progressively rotated and time-shifted according to the polarization directions (eigenvectors) and phase velocities (eigenvalues) from the Christoffel matrix $\left(m_{i k}\right)$ for each well-resolved block touched in the local $S$ model

$$
m_{i k}=\frac{1}{\rho(z)} c_{i j k l}(z) \hat{n}_{j} \hat{n}_{l},
$$

where $\rho$ is density and a function of depth $z$ (i.e., pressure and temperature), $c_{i j k l}$ is the elastic stiffness tensor of an olivine-opx crystal (also a function of P and T; Table S1), and $\hat{n}$ is ray propagation direction [e.g., Babuska and Cara, 1991]. This method is nearly identical to the forward calculation of predicted splitting utilized in the local $S$ inversion [Abt and Fischer, 2008; Abt et al., 2009] except that here we (1) apply the time shift in the reverse order (i.e., the fast and slow components are shifted backward and forward in time, respectively) and (2) are working with real wave- forms and not synthetic wavelets. Abt et al. [2009] provide a complete description of the wedge anisotropy model, including block dimensions and model resolution.

[13] Splitting parameters calculated from the resulting "backed out" waveforms (e.g., Figure 8) provide us with a means of constraining the orientation and strength of anisotropy in the mantle outside the portion of the wedge sampled by local $S$ waves (i.e., further and deeper into the back-arc wedge and beneath the subducting slab). An assumption of the maximum depth of anisotropy, somewhere between the core-mantle boundary and the surface, must be made, and here we choose this depth to be the top of the transition zone at $410 \mathrm{~km}$. Comparisons of shear wave splitting between deep-focus earthquakes and SKS phases show that in general almost no splitting occurs on subvertical paths in the transition zone and lower mantle, although transition zone splitting does appear to occur in isolated regions [Fischer and Wiens, 1996; Fouch and Fischer, 1996]. Decreasing (increasing) the anisotropy cutoff depth in our models would simply increase (decrease) the strength of anisotropy inferred from the corrected $S K(K)$ $S$ splitting measurements. We assume the same elastic constants used in the local $S$ model (i.e., $70 \%$ olivine [Anderson and Isaak, 1995; Abramson et al., 1997] and 30\% opx [Frisillo and Barsch, 1972] with hexagonal symmetry and the olivine $a$ axis as the symmetry axis; Table S1).

[14] This approach assumes $S K(K) S$ waves, which have dominant frequencies of $0.05-0.1 \mathrm{~Hz}$ (wavelengths of $\sim 50-100 \mathrm{~km}$ ), are affected by mantle wedge anisotropy in the same manner as local $S$ waves, with dominant frequencies of $0.5-1 \mathrm{~Hz}$ (wavelengths of $\sim 5-10 \mathrm{~km}$ ). If anisotropy in the shallow wedge, as sampled and imaged by local $S$ waves, is the result of structure (e.g., LPO, aligned melt) that varies

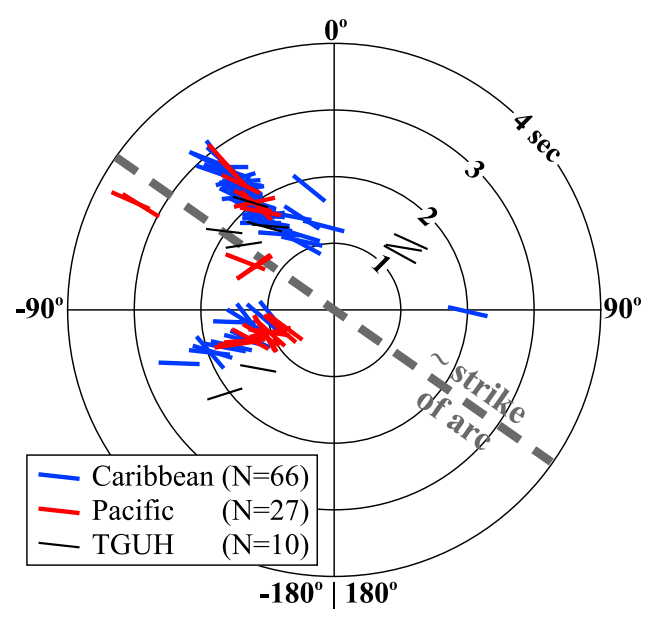

Figure 5. $S K(K) S$ splitting parameters plotted radially as a function of back azimuth and delay time. Vector orientation is parallel to fast direction, with up being north. Splits at TUCAN stations from waves that sample predominantly Caribbean mantle are blue, and those sampling mostly Pacific mantle are red (see Figure 6 for raypaths). Black vectors are splits at station TGUH. Again, the approximate strike of the arc is shown with the dashed gray line. 


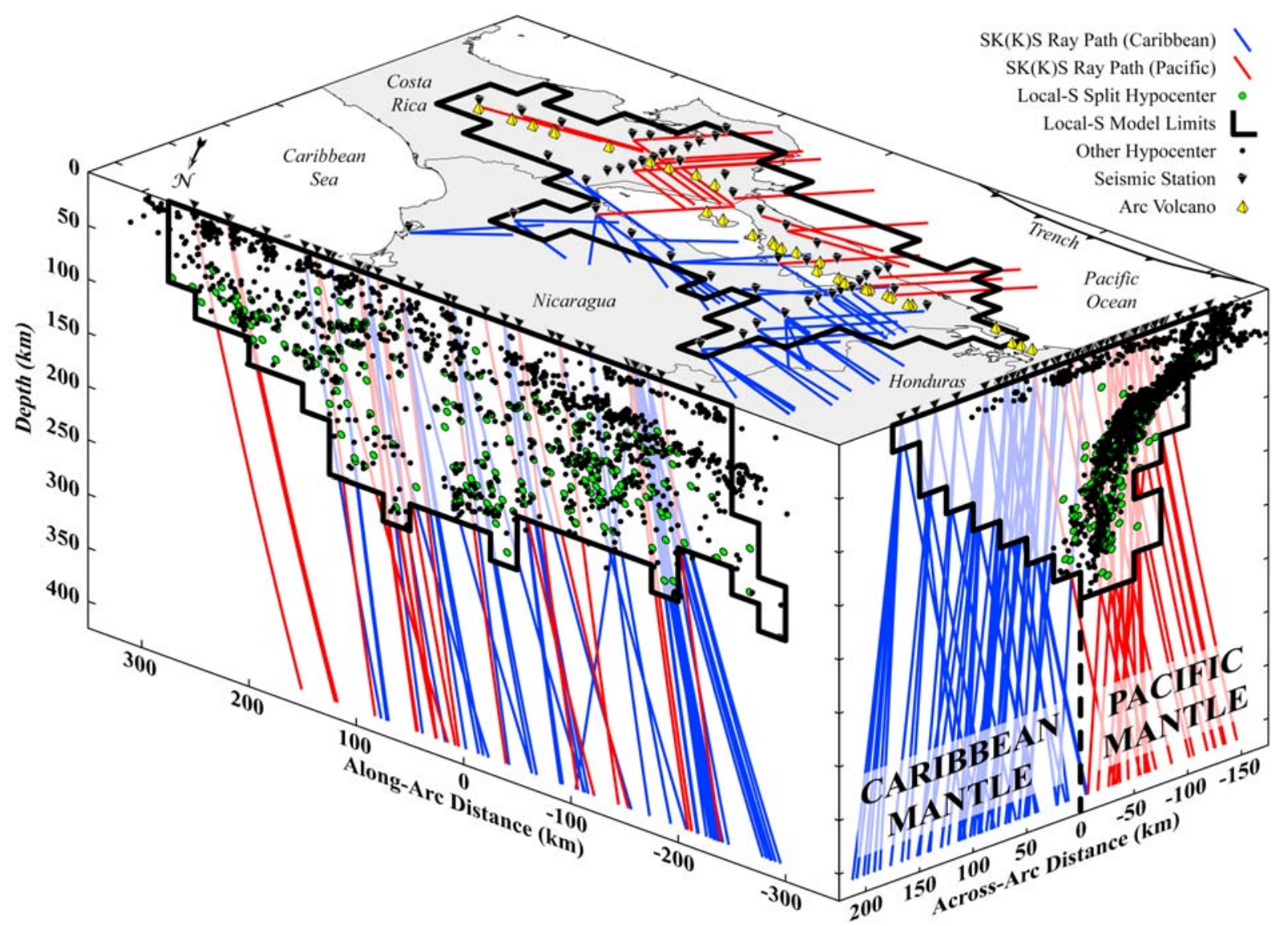

Figure 6. TUCAN $S K(K) S$ raypaths beneath Costa Rica and Nicaragua and through the local $S$ splitting tomography model space. Rays are traced through AK135 [Kennett et al., 1995]; blue paths are those dominantly traveling through Caribbean upper mantle (i.e., deeper wedge), and red paths are those dominantly in Pacific mantle (i.e., subslab). The limits of the well-resolved model space from local $S$ tomography are shown with the thick black line. Hypocenters from local $S$ splits are the green circles, and the remainder of the relocated local event catalog [Syracuse et al., 2008] is shown with smaller black circles.

with a length scale greater than local $S$ wavelengths but less than $S K(K) S$ wavelengths, then $S K(K) S$ waves would effectively sense an average of the finer-scale anisotropic structure in the local $S$ model. The local $S$ model was parameterized with $25^{3} \mathrm{~km}^{3}$ blocks, and individual blocks in the back-arc regions of the model were combined into larger volumes (50 km vertically by up to $100 \mathrm{~km}$ laterally). Consequently, $S K(K) S$ waves might be expected to smooth/ average the anisotropy in regions of the local $S$ model beneath the arc and fore arc. $S K(K) S$ path lengths through the local $S$ model and subsequent delay times accrued by $S K(K) S$ waves are generally small; on average, the delay times from the backed out splits differ from those observed at the surface by only $0.12 \mathrm{~s}(\min =-0.62 \mathrm{~s}, \max =0.5 \mathrm{~s})$. Therefore, accounting for finite $S K(K) S$ wavelengths in the local $S$ model would not likely dramatically change the resulting anisotropy models calculated here.

\subsection{Best Fitting Models of Crystallographic Orientation}

[15] The number of $S K(K) S$ splitting measurements (93 to TUCAN stations) is almost an order of magnitude smaller than for local $S$ (791), and both the distribution of events for the $S K(K) S$ measurements and their near-vertical incidence result in very few crossing raypaths (Figure 6), unlike with local $S$ raypaths [see Abt et al., 2009, Figure 7]. Therefore, we do not attempt to tomographically invert for crystallographic orientation using the backed out $S K(K) S$ waveforms. Instead, we simply conduct a grid search over all possible symmetry axis orientations and strengths of anisotropy (Figure 9). We search symmetry axis azimuths $(\theta)$ from $-180^{\circ}$ to $180^{\circ}$ at $10^{\circ}$ increments, symmetry axis dips $(\psi)$ from $0^{\circ}$ to $90^{\circ}$ at $10^{\circ}$ increments, and anisotropy strengths $(\alpha)$ from $0 \%$ to $100 \%$ at $10 \%$ increments.

[16] For each $S K(K) S$ raypath, a synthetic wavelet with random noise and a signal-to-noise ratio of 10 (typical for our observed $S K(K) S$ waves) is set as the SV component of motion (SH is random noise) at $410 \mathrm{~km}$ and propagated up through the model (blocks $25 \mathrm{~km}$ on each side) until reaching the local $S$ model space (thick black line in Figure 6). Splitting of the resulting synthetic wavelet is calculated at this entry point in the local $S$ model in the same manner as with the real data and then compared with the observed 
Table 2. $S K(K) S$ Event Origin Times and Location Information ${ }^{\mathrm{a}}$

\begin{tabular}{|c|c|c|c|c|c|c|c|}
\hline $\begin{array}{c}\text { Origin Time } \\
\text { (YEAR.JDY.HH.MM.SS) }\end{array}$ & $\begin{array}{l}\text { Latitude } \\
\text { (deg) }\end{array}$ & $\begin{array}{l}\text { Longitude } \\
\text { (deg) }\end{array}$ & $\begin{array}{l}\text { Depth } \\
(\mathrm{km})\end{array}$ & $\begin{array}{c}\text { Magnitude } \\
M_{w}\end{array}$ & $\begin{array}{l}\text { Back Azimuth } \\
\text { (deg) }\end{array}$ & $\begin{array}{l}\text { Distance } \\
\text { (deg) }\end{array}$ & $\begin{array}{l}\text { Number of } \\
\text { Splits }\end{array}$ \\
\hline 2004.249 .10 .07 .07 & 136.62 & 33.07 & 14 & 7.2 & 320 & 120 & 1 \\
\hline 2004.250 .23 .29 .35 & 137.23 & 33.21 & 10 & 6.6 & 319 & 120 & 4 \\
\hline 2004.282 .08 .27 .53 & 162.16 & -10.95 & 36 & 6.9 & 263 & 114 & 4 \\
\hline 2004.316 .17 .34 .52 & 162.21 & -11.13 & 10 & 6.7 & 263 & 114 & 1 \\
\hline 2004.322 .21 .09 .13 & -178.71 & -20.07 & 622 & 6.6 & 251 & 97 & 6 \\
\hline 2004.333 .18 .32 .14 & 145.12 & 43.01 & 39 & 323 & 7.0 & 109 & 25 \\
\hline 2004.341 .14 .15 .11 & 145.23 & 42.9 & 35 & 323 & 6.8 & 109 & 16 \\
\hline 2004.361.04.21.29 & 92.96 & 6.91 & 39 & 7.5 & 5 & 162 & 0 \\
\hline 2005.036 .12 .23 .18 & 123.34 & 5.29 & 525 & 7.1 & 299 & 147 & 5 \\
\hline 2005.100 .10 .29 .11 & 99.61 & -1.64 & 19 & 6.7 & 332 & 169 & 4 \\
\hline 2005.101 .12 .20 .05 & 145.91 & -3.48 & 11 & 6.7 & 275 & 128 & 0 \\
\hline 2005.132 .11 .15 .35 & -139.23 & -57.38 & 10 & 6.5 & 206 & 82 & 0 \\
\hline 2005.134 .05 .05 .18 & 98.46 & 0.59 & 34 & 6.8 & 342 & 167 & 1 \\
\hline 2005.165 .17 .10 .12 & 179.31 & 51.24 & 17 & 6.8 & 321 & 84 & 0 \\
\hline 2005.323 .14 .10 .13 & 96.79 & 2.16 & 21 & 6.5 & 350 & 166 & 2 \\
\hline 2005.336 .13 .13 .09 & 142.12 & 38.09 & 29 & 6.5 & 321 & 113 & 5 \\
\hline 2005.339 .12 .19 .56 & 29.83 & -6.22 & 22 & 7.2 & 91 & 116 & 1 \\
\hline 2006.002 .06 .10 .49 & -21.61 & -60.96 & 13 & 7.4 & 154 & 88 & 0 \\
\hline 2006.002 .22 .13 .40 & -178.18 & -19.93 & 582 & 7.2 & 251 & 96 & 18 \\
\hline 2007.271.13.38.57 & 142.67 & 22.01 & 260 & 7.5 & 306 & 119 & 2 \\
\hline 2007.354 .07 .55 .15 & 178.29 & -39.01 & 20 & 6.6 & 232 & 102 & 2 \\
\hline 2008.045 .10 .09 .22 & 21.67 & 36.5 & 29 & 6.9 & 50 & 96 & 1 \\
\hline 2008.063.09.31.02 & 153.18 & 46.41 & 10 & 6.5 & 323 & 99 & 1 \\
\hline 2008.197 .03 .26 .35 & 27.71 & 35.99 & 52 & 6.5 & 48 & 101 & 2 \\
\hline 2008.201.02.39.28 & 142.21 & 37.55 & 22 & 7.0 & 320 & 111 & 1 \\
\hline 2008.205 .15 .26 .20 & 141.47 & 39.81 & 111 & 6.8 & 322 & 110 & 1 \\
\hline
\end{tabular}

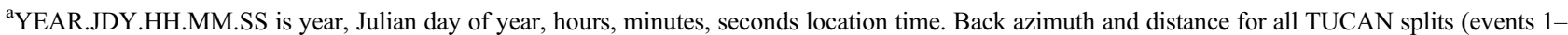
93) are measured from a rough estimate of the TUCAN seismic array center: $11.5^{\circ} \mathrm{N}, 85.5^{\circ} \mathrm{W}$. For TGUH, the back azimuth and distance are measured from the station.

backed out splitting measurement from the corresponding ray. The weighted misfits for fast direction $\left(\varepsilon_{\phi}\right)$ and delay time $\left(\varepsilon_{d t}\right)$ from $N$ splitting measurements are

$$
\varepsilon_{\phi, d t}=\frac{\sum_{i=1}^{N}\left[\left(\phi, d t_{i}^{o b s}-\phi, d t_{i}^{p r e d}\right)\left[\left(\sigma_{\phi, d t_{i}}^{\text {obs }}+\sigma_{\phi, d t_{i}}^{\text {pred }}\right) / 2\right]^{-1}\right]}{\sum_{i=1}^{N}\left[\left(\sigma_{\phi, d t_{i}}^{\text {obs }}+\sigma_{\phi, d t_{i}}^{\text {pred }}\right) / 2\right]^{-1}}
$$

where $\sigma^{o b s}$ and $\sigma^{\text {pred }}$ are the half width of the $95 \%$ confidence region for the observed backed out and synthetic splitting parameters, respectively, at the entry point in the local $S$ model. The fast direction and splitting time misfits are then normalized by their maximum respective value, and the average of the two yields a combined measure of misfit for a particular set of model parameters $(\alpha, \theta, \psi)$,

$$
\varepsilon^{\text {norm }}(\alpha, \theta, \psi)=\frac{\left|\varepsilon_{\phi} / \varepsilon_{\phi}^{\max }\right|+\left|\varepsilon_{d t} / \varepsilon_{d t}^{\max }\right|}{2}
$$

[17] The resulting misfit volumes are presented as "slices" through the normalized misfit minimum (Figure 9g) for both the Caribbean (Figures 9a-9c) and Pacific mantle (Figures 9d-9f). The 95\% confidence limits for the best fitting combination of model parameters for each region were calculated using a bootstrap approach and are shown by the yellow shading around the best fitting model parameters (Figure 9). Because splitting is dependent on the relationship between crystallographic orientation and ray propagation direction (as well as initial polarization), some combinations of raypaths and model parameters will result in unstable or null measurements. We characterized null measurements in the synthetic waveforms by fast direction errors of $>70^{\circ}$ and delay time errors of $>75 \%$ of $d t$, and experimented with different approaches for treating null measurements in the misfit calculation. In the misfit results presented in Figure 9, paths where a given model predicts a null measurement are excluded for that model in the weighted misfit calculation. In

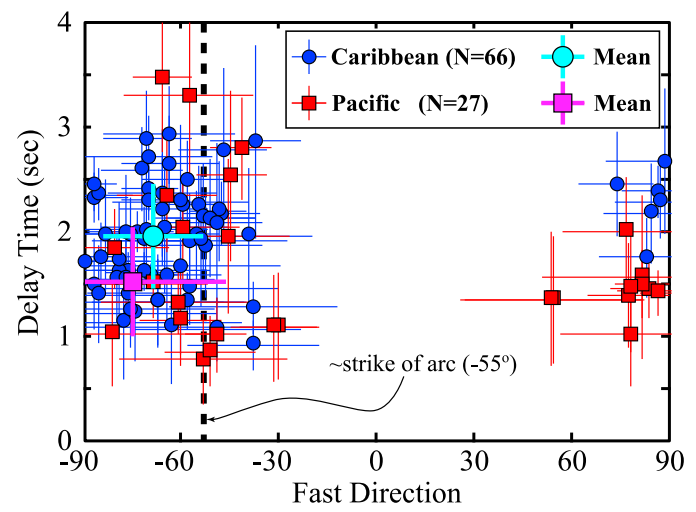

Figure 7. Comparison of splitting parameters from waves sampling Caribbean and Pacific mantle. The mean values for the two regions are shown with the larger cyan circle (Caribbean) and magenta square (Pacific), with the bars representing \pm 1 standard deviation. The smaller blue circles and red squares (with standard splitting errors) are the individual splitting parameters for the Caribbean and Pacific paths, respectively. The Pacific splits have a smaller mean $d t$ relative to Caribbean splits $(0.30 \mathrm{~s}$ or $\sim 15 \%)$ and also display less coherence in both $\phi$ and $d t$. 

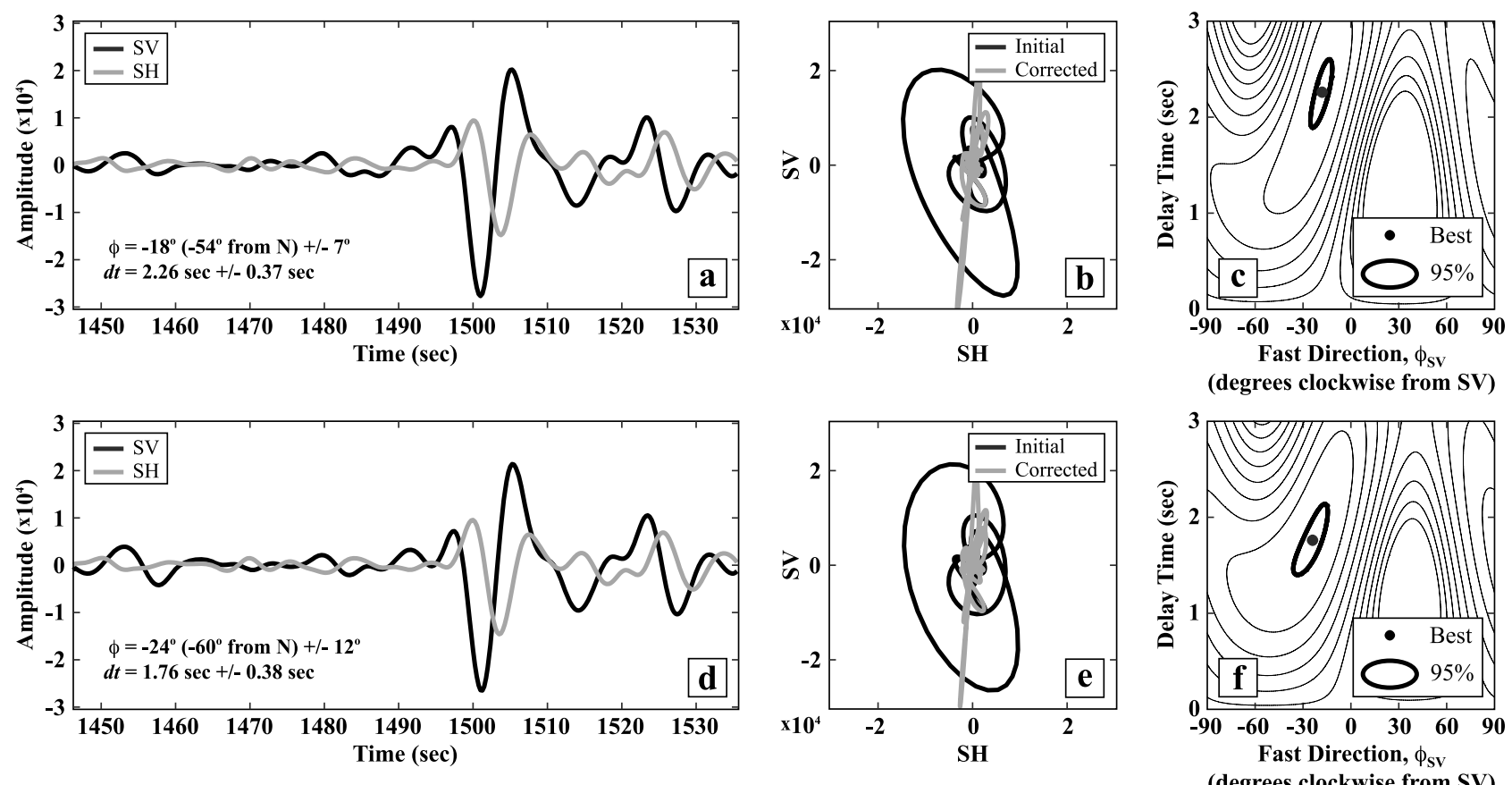

Figure 8. Example of backing out the effects of anisotropy in the local $S$ splitting tomography model [Abt et al., 2009] on $S K(K) S$ waveforms. (a-c) Same as Figures 3a-3c. (d) The waveforms particle motion. (e) Best fitting splitting parameters. (f) After accounting for anisotropy in six well-resolved local $S$ blocks over a path length of $127 \mathrm{~km}$ (i.e., the expected observation at the entry point in the local $S$ model). Although the two sets of waveforms, particle motions, and $\lambda_{2}$ surfaces look almost identical to the eye (due to the relatively long analysis window), the delay time for each is modestly different: $1.76 \mathrm{~s}$ at the local $S$ model entry point compared with $2.26 \mathrm{~s}$ at the surface ( $28 \%$ larger at the surface). We use these estimated splitting parameters (Figures $8 \mathrm{~d}-8 \mathrm{f}$ ) to establish the orientation of anisotropy outside the shallow mantle wedge.

addition, if more than $50 \%$ of the raypaths from a region for a combination of model parameters result in null measurements, then we consider that model to be unacceptable. These cases most often occur for small strengths of anisotropy (e.g., small values of $\alpha$ and/or larger values of $\psi$ ) and for azimuths roughly parallel or perpendicular to the raypaths. The result of excluding these sets of model parameters is the appearance of "holes" in the misfit volume (gray regions in Figures 9a-9f). For the best fitting Caribbean model parameters, no measurements were excluded for unstable/ null-like behavior, while only two were excluded for the best fitting Pacific model. Misfits were also calculated including these predicted null measurements are their associated errors, and the resulting range of model parameters deemed to provide acceptable fits to the data are similar to those shown in Figure 9.

[18] As expected, given the coherent arc-parallel pattern of $S K(K) S$ fast directions (Figures 1, 4, 5, and 7), the best fitting symmetry axis azimuth for both regions is roughly arc-parallel: $\theta=-70^{\circ}$ for the Caribbean mantle, and $\theta=$ $-80^{\circ}$ for the Pacific mantle. The $95 \%$ confidence regions indicate that $\theta$ is relatively well constrained, with uncertainties of $<20^{\circ}$. In contrast, much larger trade-offs exist between the dip and strength of anisotropy. The best fitting models show only minor differences between the two regions: $\psi=30^{\circ}$ and $\alpha=30 \%$ for the Caribbean mantle, and $\psi=10^{\circ}$ and $\alpha=20 \%$ for the Pacific mantle. These best fitting symmetry axes are dipping slightly toward the westnorthwest, very similar to the relatively horizontal and dominantly arc-parallel symmetry axes imaged in the shallow wedge by local $S$ splitting tomography [Abt et al., 2009]. However, for the Caribbean mantle, the 95\% confidence region around the best fitting model encompasses dip and strength parameters from $\psi=10^{\circ}, \alpha=20 \%$ to $\psi=80^{\circ}, \alpha=$ $80 \%$, and shallow and steep dips also provide acceptable fits to the Pacific data (Figure 9e). This particular trade-off between strength and dip is expected given the decrease in anisotropy sampled by near-vertical shear phases as the fast symmetry axis of the elastic coefficients rotates from horizontal to vertical (Figure S1).

\section{Implications for Mantle Flow}

[19] Assuming the origin of observed anisotropy is A-type dislocation creep in olivine [e.g., Zhang and Karato, 1995], the best fitting symmetry axis orientations and their $95 \%$ confidence limits (Figure 9) indicate that a component of horizontal flow in the along-arc direction occurs in the Caribbean mantle beneath southeastern Central America, and that such flow is also likely, although not technically required, on the Pacific side of the subducting Cocos plate. In both mantle regions, the best fitting model parameters suggest a relatively large component of along-arc flow that results in a fast symmetry axis that is aligned roughly par- 
allel to the arc with a shallow $\operatorname{dip}\left(\sim 30^{\circ}\right.$ for the Caribbean mantle, $\sim 10^{\circ}$ for the Pacific mantle). Taking the $95 \%$ confidence limits of the best fitting model parameters into account, both shallower and steeper dips are acceptable for the Caribbean mantle. Although a steeper dip could imply a smaller component of horizontal flow, because the azimuth of the fast symmetry axis remains parallel to the arc as dip increases and the dip never reaches $90^{\circ}$, some flow parallel to the slab/arc is still required. In addition, the steepest possible fast symmetry axes $\left(\sim 80^{\circ}\right)$ are unlikely because they would imply an $80 \%$ alignment of olivine grains. This strength of olivine fabric is not typically observed in naturally or experimentally deformed samples [Zhang and Karato, 1995; Mainprice et al., 2000; Jung et al., 2006]. On the Pacific side, along-arc flow is not technically required because the $95 \%$ confidence limits overlap cases with a vertical fast symmetry axis. However, exactly vertical $a$ axes would be an unlikely scenario, given that the dip of the slab does not exceed $70^{\circ}$ at depths of $200 \mathrm{~km}$ or less [Syracuse et al., 2008] and remains nonvertical into the lower mantle [Ren et al., 2007]. In the more likely case that the fast symmetry axis has a dip of $<90^{\circ}$, some component of along-arc flow would be required to produce the range of fast symmetry axis azimuths. Thus, in the Caribbean mantle, the observed splitting and the acceptable range of anisotropy models rule out purely arc-normal flow as would be predicted by simple entrainment of mantle by the slab; in the Pacific mantle, purely arc-normal flow is unlikely.

[20] Some recent studies have proposed that the arc-parallel shear wave splitting common to stations in subduction zone arc and near-arc settings may be largely explained by very strong anisotropy due to hydrous phases (such as ser-
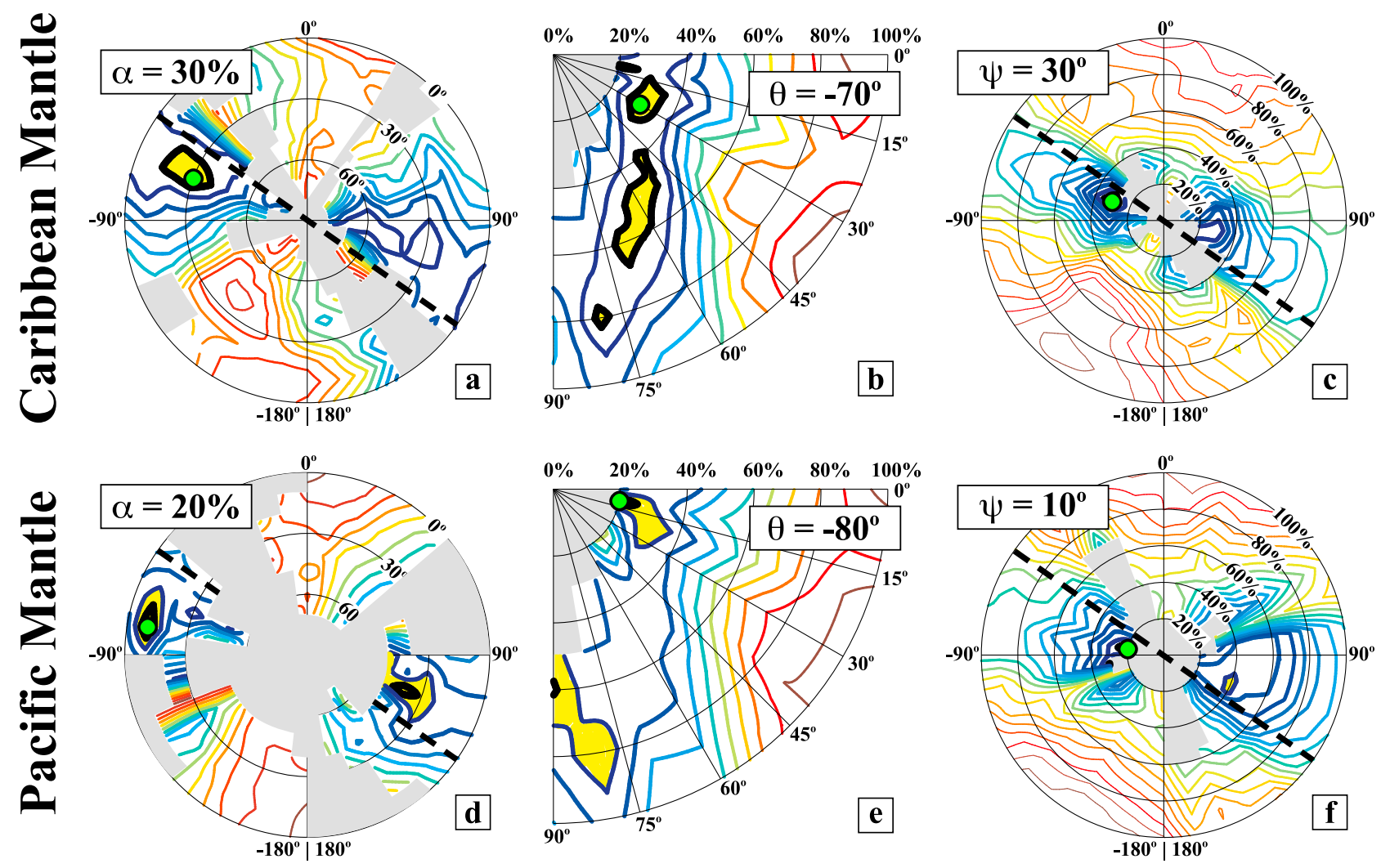

Caribbean Mantle
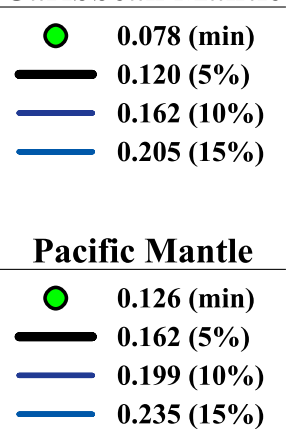

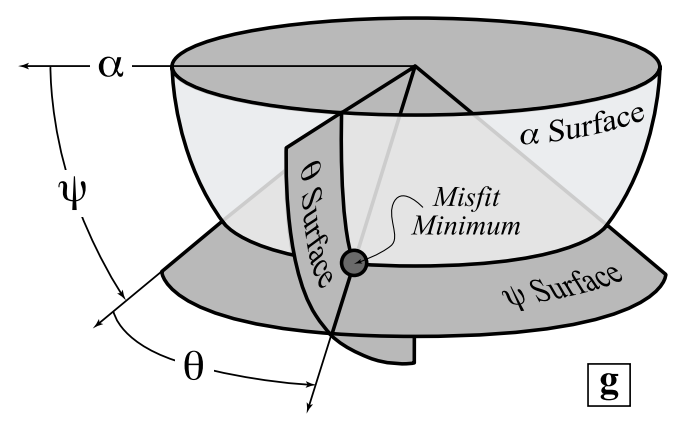

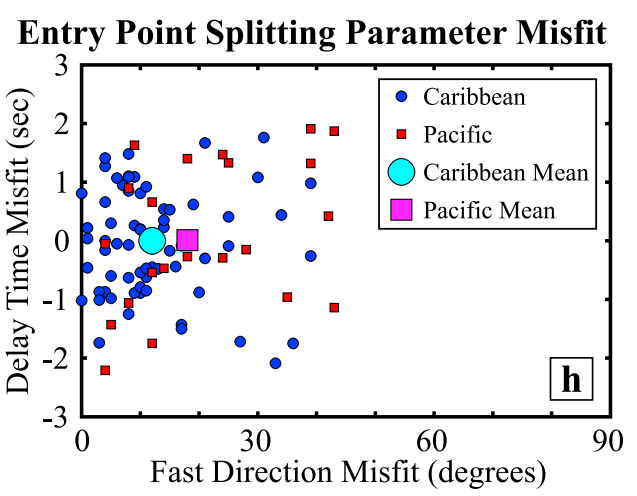

Figure 9 
pentine) on faults within the subducting slab [Faccenda et al., 2008, 2009; Healy et al., 2009]. However, this mechanism does not appear to strongly influence the $S K(K) S$ splitting modeled in this study. First, its effects are not evident in the local $S$ splitting recorded at TUCAN stations [Abt et al., 2009]. Because faulting is thought to penetrate into the top of slab by no more than $20-30 \mathrm{~km}$ [Faccenda et al., 2009], the associated anisotropy would need to be very large in order to match $S K(K) S$ splitting times typical of the TUCAN stations or splitting in other subduction zones (1-3 s) [Faccenda et al., 2008; Healy et al., 2009]. Although the ray angles of the local $S$ phases recorded by the TUCAN stations are more variable than those of the $S K(K) S$ phases, a highly anisotropic layer in the upper slab would still produce significant splitting in local $S$ phases, particularly in Nicaragua where relocated hypocenters [Syracuse et al., 2008] are distributed through the upper $20 \mathrm{~km}$ of the slab. Although anisotropy in the slab was not isolated in the local $S$ tomography, if strong slab anisotropy did exist, its effects should be reflected in the local $S$ model. However, the local $S$ model blocks nearest the slab do not manifest particularly large anisotropy [Abt et al., 2009]. In addition, averaged local $S$ splitting times systematically increase with the path length, pointing to the mantle wedge (not the upper slab) as the dominant source of anisotropy [Abt et al., 2009]. Nonetheless, systematic modeling of local $S$ splitting to bound the strength of anisotropy in the upper slab would be an interesting future study. A second point is that the $S K(K)$ $S$ splitting observations modeled in this study have been corrected for the anisotropy model based on local $S$ tomography. Therefore, they should be largely free of the effects of slab anisotropy down to the depths of the local $S$ events ( $\sim 10 \mathrm{~km}$ into the slab in Costa Rica and $\sim 20 \mathrm{~km}$ into the slab in Nicaragua) with the caveat that $S K(K) S$ and local $S$ incidence angles are not everywhere identical.

[21] Previous studies provide a broader context for the Central American anisotropy models presented here. Russo and Silver [1994] hypothesized that teleseismic $S$ and SKS arc-parallel fast polarization directions along the Andean margin are the result of roll-back of the Nazca Plate forcing Pacific mantle to the north and south of where flat slab subduction is occurring (orange arrows in Figure 10). Subsequent splitting observations in the Caribbean and Scotia Seas [Russo et al., 1996, Müller et al., 2008; PiñeroFeliciangeli and Kendall, 2008; Growdon et al., 2009] indicate this flow likely wraps around the edges of the Nazca Plate (empty dashed arrow in Figure 10), a pattern consistent with the Caribbean and Scotia Plates being driven eastward relative to South America as the Pacific mantle shrinks and the Atlantic/Caribbean mantle grows [e.g., Elsasser, 1971; Alvarez, 1982; Garfunkel et al., 1986]. The tectonic feature allowing mantle to flow north from the Pacific realm into the Caribbean and often invoked to explain geochemical and seismological observations [e.g., Herrstrom et al., 1995; Johnston and Thorkelson, 1997; Sallarès et al., 2000; Abratis and Wörner, 2001] is generally thought to be a young $(<10 \mathrm{Ma})$ slab window beneath southern Costa Rica, Panama, and northwestern Colombia, separating the Cocos and Nazca plates (Figure 10b). Global isotropic velocity tomography models (e.g., see $\mathrm{Li}$ et al. [2008] for $V_{P}$ and Ritsema et al. [2004] for $V_{S}$ ) may also indicate the absence of the Cocos Plate in this same region; the models lack clear evidence of high velocity anomalies in the upper mantle beneath southeastern Central America, as would be expected with the presence of a relatively cold slab.

[22] Mantle flow to the north through a slab window and into the mantle wedge beneath Costa Rica and Nicaragua is consistent with the local $S$ splitting tomography model as well as trends in $\mathrm{Pb}$ and $\mathrm{Nd}$ isotope ratios that imply a northwest direction of wedge flow [Hoernle et al., 2008; Abt et al., 2009]. This interpretation could also be used to explain the deeper wedge anisotropy constrained by $S K(K) S$ waves on the Caribbean side of the Cocos Plate (Figure 6). Beneath the Cocos Plate, the Pacific $S K(K) S$ splitting observations (Figures 5-7) and corresponding model of

\footnotetext{
Figure 9. Results of a grid search over symmetry axis azimuth $(\theta)$, symmetry axis dip $(\psi)$, and strength of anisotropy $(\alpha)$ for the model of anisotropy that minimizes misfit between predicted splitting parameters and those estimated from waveforms at their entry point in the local $S$ splitting tomography model (i.e., the shallow mantle wedge). (g) The surfaces in Figures $9 \mathrm{a}-9 \mathrm{f}$ are schematically illustrated relative to the volume of parameter space searched. Note that because of the symmetry of the elastic tensor, we only need to search the lower hemisphere (i.e., dips down from horizontal). The surfaces in Figures 9a-9c are contoured at 5\% increments between the minimum (0.078) and maximum (0.923) normalized misfit values for the Caribbean mantle splits, and the normalized misfit range for Pacific splits $(0.126-0.853)$ is contoured in Figures 9d-9f; note that contours between the Caribbean and Pacific plots do not represent exactly the same misfit values. The $95 \%$ confidence limits on the best fitting model parameters from a bootstrap test are shown by the yellow shading. (a, d) Surfaces with a constant strength of anisotropy (the best fitting $\alpha$ is $30 \%$ for the Caribbean mantle and 20\% for the Pacific). (b, e) Surfaces with a constant symmetry axis azimuth (the best fitting $\theta$ is $-70^{\circ}$ for the Caribbean mantle and $-80^{\circ}$ for the Pacific). (c, f) Surfaces with a constant symmetry axis dip (the best fitting $\psi$ is $30^{\circ}$ for the Caribbean mantle and $10^{\circ}$ for the Pacific). Note the apparent $180^{\circ}$ symmetry for $\theta$ (i.e., in Figures $9 \mathrm{a}, 9 \mathrm{c}, 9 \mathrm{~d}$, and $9 \mathrm{f}$ ); this is a result of the symmetry of the stiffness tensor and is not perfect here because of the nonuniform and nonvertical $S K(K) S$ propagation directions. The gray regions show the combinations of model parameters that resulted in more than $50 \%$ of the predicted splitting parameter measurements being unstable or null-like. The dashed black line in Figures 9a, 9c, 9d, and 9f shows the approximate strike of the arc. (h) The splitting parameter misfits for these best fitting models. The mean weighted misfit for Pacific mantle entry point splitting fast directions is greater than that for Caribbean splits $\left(18^{\circ}\right.$ versus $\left.12^{\circ}\right) ; 67 \%$ and $83 \%$ of fast directions are fit within their 95\% confidence limits for the Pacific and Caribbean regions, respectively. Delay times are both under predicted $(d t$ misfit $>0)$ and over predicted $(d t$ misfit $<0)$, resulting in mean weighted $d t$ misfits of 0.01 and $0.00 \mathrm{~s}$ for the Pacific and Caribbean splits, respectively; the mean weighted $|d t|$ misfits are $1.00 \mathrm{~s}$ and $0.72 \mathrm{~s} .67 \%$ and $44 \%$ of splitting times are fit within their $95 \%$ confidence limits for the Pacific and Caribbean regions, respectively.
} 

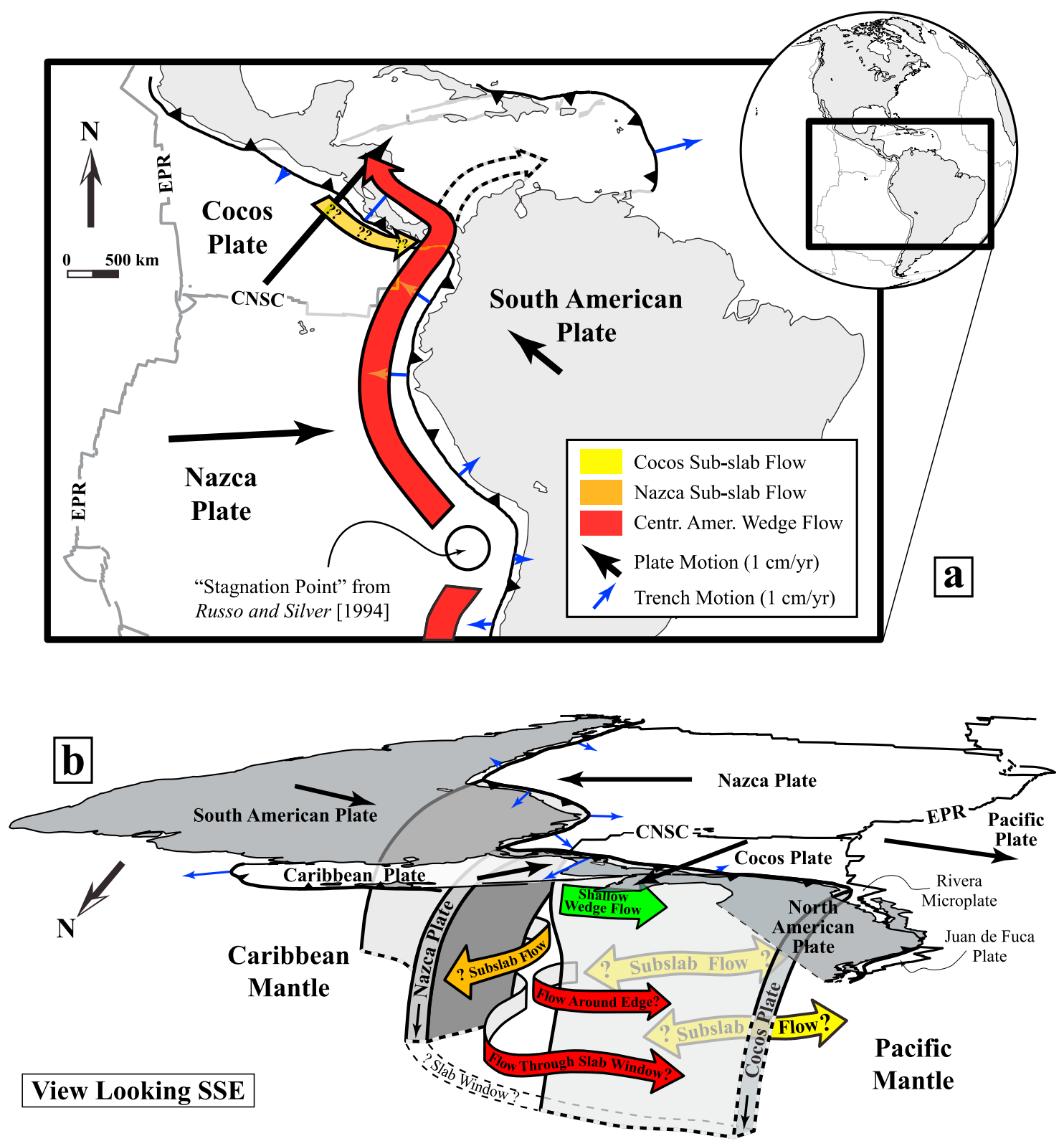

Figure 10. Regional mantle flow inferred from $S K(K) S$ and local $S$ splitting observations and modeling. (a) Map view and (b) three-dimensional schematic view looking south-southeast. The large colored arrows illustrate mantle flow, with yellow showing flow beneath the Cocos Plate, orange representing flow beneath the Nazca Plate [Russo and Silver, 1994], and red showing flow in the Central American mantle wedge. The empty dashed arrow is inferred from splitting observations in the Caribbean [e.g., Russo and Silver, 1994; Russo et al., 1996]. The green arrow in Figure 10b illustrates shallow mantle wedge flow imaged by local $S$ splitting tomography [Abt et al., 2009]. We display the slight dip of inferred subslab and deeper wedge flow with the yellow and red arrows in Figure 10b, but as discussed in sections 3.2 and 4 , the dip of anisotropy/flow is not uniquely resolved. Black and blue arrows show plate and trench motions from Schellart et al. [2008] [i.e., DeMets et al., 1994; O'Neill et al., 2005]; vector lengths indicate velocity. The westward pointing blue arrows on the Andean trench show trench retreat, and the two vectors on the Middle America trench show the along-strike change in motion (i.e., counterclockwise rotation of the Cocos slab) discussed in section 4. The East Pacific Rise (EPR) and Cocos Nazca Spreading Center (CNSC) are labeled.

anisotropy (Figures 9d-9f) imply flow roughly parallel to slab strike, but the direction of flow (west-northwest versus eastsoutheast) is not observationally constrained.
[23] Although these hypothesized flow patterns are based on observed shear wave splitting and, in some cases, geochemical data, the physical drivers of such flow have not yet been fully demonstrated, but neither has such flow been 
shown to be implausible. In either the Indo-Atlantic hot spot reference frame [DeMets et al., 1994; O'Neill et al., 2005] (corresponding to the plate and trench motions in Figure 10) or the Pacific hot spot reference frame [Gripp and Gordon, 2000], the South American trench (and presumably the Nazca slab) are retreating [Schellart et al., 2007, 2008]. Slab retreat tends to drive mantle beneath the slab around the slab edge [Buttles and Olsen, 1998; Kincaid and Griffiths, 2003; Funiciello et al., 2006; Schellart et al., 2007; Honda, 2009]. While it is not clear from existing models that subslab flow would be strongly aligned with the strike of the slab over the thousands of kilometers, it has been suggested that a low viscosity zone in the mantle just beneath the slab could enhance the development of focused along-arc flow [Long and Silver, 2008, 2009].

[24] In the region sampled in this study, the motions of the Middle America trench and Cocos slab would also play a role in generating and focusing mantle flow. In the IndoAtlantic plate motion reference frame (Figure 10), the Middle America trench is retreating at its northern end and advancing in the south, while in the Pacific reference frame, it is retreating along its entire length [Schellart et al., 2008]. However, regardless of reference frame, a relative increase in southwestward trench migration occurs along strike from Costa Rica to southern Mexico, indicating a counterclockwise rotation of the trench. Crustal compression in Costa Rica and extension in Nicaragua, along with the progressive trenchward migration of the volcanic arc in northern $\mathrm{Ni}$ caragua, are consistent with this plate motion model and suggest that this type of motion has been relatively longlived (at least since the early Miocene [Weinberg, 1992]). The flow implications of this along-arc variation in trench and slab migration remain to be modeled. However, the trench rotation could draw mantle wedge material to the northwest, particularly if along-arc flow is enhanced by a low viscosity layer in the wedge above the slab, as suggested by Abt et al. [2009]. Subslab mantle under these conditions could be driven to the east-southeast (yellow arrows in Figure 10) and possibly entrained with the northward flow of mantle from beneath the Nazca Plate and forced through the slab window.

\section{Conclusions}

[25] The primary objective of this study was to constrain the orientation of anisotropy outside the shallow mantle wedge beneath Costa Rica and Nicaragua. The observed $S K$ $(K) S$ splitting in the Caribbean (deeper back-arc wedge) and Pacific (subslab) mantle is best fit by anisotropy whose fast symmetry axis (i.e., olivine $a$ axis) has an azimuth roughly parallel to the arc and a shallow dip. In the Caribbean mantle, steeply dipping symmetry axes (up to $80^{\circ}$ ) are permitted by the modeling confidence limits, but would require an unrealistically strong fabric alignment. In the Pacific mantle, vertical alignment of symmetry axes lies within the modeling confidence limits, but is unlikely given the nonvertical trajectory of the subducting slab. In order to produce the anisotropy that falls within the range of acceptable scenarios, a significant component of along-arc flow is required in the Caribbean mantle and is highly likely in the Pacific mantle.
[26] The anisotropy in the Caribbean mantle combined with isotopic data indicates along-arc flow to the WNW [Hoernle et al., 2008; Abt et al., 2009]. Such flow could originate from a slab window to the southeast beneath southern Costa Rica and Panama, as has been inferred in numerous previous studies [Russo and Silver, 1994; Herrstrom et al., 1995; Johnston and Thorkelson, 1997; Abratis and Wörner, 2001; Hoernle et al., 2008; Abt et al., 2009]. Flow beneath the Cocos Plate also likely has a component that is roughly parallel to the strike of the slab. In contrast to wedge flow, the absolute direction of subslab flow is unconstrained by geochemical data, but subslab flow could be driven ESE by along-arc gradients in slab rollback as well as regional trench and plate motions.

[27] Acknowledgments. Pedro Pérez, Allan Morales, Catherine Rychert, Ellen Syracuse, Laura MacKenzie, Mariela Salas-de la Cruz, Alexis Walker, Gustavo Reyes, and Tim Parker were instrumental in the TUCAN seismic array deployment, maintenance, and demobilization. The IRIS/PASSCAL program provided seismometers for the TUCAN Seismic Experiment. We also thank Heather Ford, McCall Burau, Tina Rau, Andy Nager, and Arjun Kohli for the splitting analysis at station TGUH. This research and the TUCAN Seismic Experiment were supported by the NSF-MARGINS Program through awards OCE-0203607, OCE-0203650, and EAR-0742282.

\section{References}

Abramson, E. H., J. M. Brown, L. J. Slutsky, and J. Zaug (1997), The elastic constants of San Carlos olivine to $17 \mathrm{GPa}$, J. Geophys. Res., 102, 12,253-12,263, doi:10.1029/97JB00682.

Abratis, M., and G. Wörner (2001), Ridge collision, slab-window formation, and the flux of Pacific asthenosphere in the Caribbean realm, Geology, 29, 127-130 doi:10.1130/0091-7613(2001)029<0127:RCSWFA>2.0.CO;2.

Abt, D. L., and K. M. Fischer (2008), Resolving three-dimensional anisotropic structure with shear-wave splitting tomography, Geophys. J. Int., 173, 859-886, doi:10.1111/j.1365-246X.2008.03757.x.

Abt, D. L., K. M. Fischer, G. A. Abers, W. Strauch, J. M. Protti, and V. González (2009), Shear wave anisotropy beneath Nicaragua and Costa Rica: Implications for flow in the mantle wedge, Geochem. Geophys. Geosyst., 10, Q05S15, doi:10.1029/2009GC002375.

Alvarez, W. (1982), Geological evidence for the geographical pattern of mantle return flow and the driving mechanism of plate tectonics, J. Geophys. Res., 87, 6697-6710, doi:10.1029/JB087iB08p06697.

Anderson, M. L., G. Zandt, E. Triep, M. Fouch, and S. Beck (2004), Anisotropy and mantle flow in the Chile-Argentina subduction zone from shear wave analysis, Geophys. Res. Lett., 31, L23608, doi:10.1029/ 2004 GL020906.

Anderson, O. L., and D. G. Isaak (1995), Elastic constants of mantle minerals at high temperature, in Mineral Physics and Crystallography: A Handbook of Physical Constants, AGU Ref. Shelf, vol. 2, edited by T. J. Aherns, pp. 64-97, AGU, Washington, D. C.

Babuska, V., and M. Cara (1991), Seismic Anisotropy in the Earth, 217 pp., Kluwer Acad., Dordrecht, Netherlands.

Barckhausen, U., C. R. Ranero, R. von Huene, S. C. Cande, and H. A. Roeser (2001), Revised tectonic boundaries in the Cocos Plate off Costa Rica: Implications for the segmentation of the convergent margin and for plate tectonic models, J. Geophys. Res., 106, 19,207-19,220, doi:10.1029/ 2001JB000238.

Buttles, J., and P. Olsen (1998), A laboratory model of subduction zone anisotropy, Earth Planet. Sci. Lett., 164, 245-262, doi:10.1016/S0012821X(98)00211-8.

Conrad, C. P., M. D. Behn, and P. G. Silver (2007), Global mantle flow and the development of seismic anisotropy: Differences between the oceanic and continental upper mantle, J. Geophys. Res., 112, B07317, doi:10.1029/2006JB004608.

DeMets, C. (2001), A new estimate for present-day Cocos-Caribbean plate motion: Implications for slip along the Central American volcanic arc, Geophys. Res. Lett., 28, 4043-4046, doi:10.1029/2001GL013518.

DeMets, C., R. G. Gordon, D. F. Argus, and S. Stein (1994), Effect of recent revisions to the geomagnetic reversal time scale on estimates of current plate motions, Geophys. Res. Lett., 21, 2191-2194, doi:10.1029/ 94GL02118. 
Elsasser, W. M. (1971), Sea-floor spreading as thermal convection, J. Geophys. Res., 76, 1101-1112, doi:10.1029/JB076i005p01101.

Faccenda, M., L. Burlini, T. V. Gerya, and D. Mainprice (2008), Fault induced seismic anisotropy by hydration in subducting oceanic plates, Nature, 455, 1097-1100, doi:10.1038/nature07376.

Faccenda, M., T. V. Gerya, and L. Burlini (2009), Deep slab hydration induced by bending-related variations in tectonic pressure, Nat. Geosci., 2, 790-793, doi:10.1038/ngeo656.

Fischer, K. M., and D. A. Wiens (1996), The depth distribution of mantle anisotropy beneath the Tonga subduction zone, Earth Planet. Sci. Lett., 142, 253-260, doi:10.1016/0012-821X(96)00084-2.

Fouch, M. J., and K. M. Fischer (1996), Mantle anisotropy beneath northwest Pacific subduction zones, J. Geophys. Res., 101, 15,987-16,002, doi:10.1029/96JB00881.

Frisillo, A. L., and G. R. Barsch (1972), Measurement of single-crystal elastic constants of bronzite as a function of pressure and temperature, J. Geophys. Res., 77, 6360-6384, doi:10.1029/JB077i032p06360.

Funiciello, F., M. Moroni, C. Pimomallo, C. Faccenna, A. Cenedese, and H. A. Bui (2006), Mapping mantle flow during retreating subduction: Laboratory models analyzed by feature tracking, J. Geophys. Res., 111 , B03402, doi:10.1029/2005JB003792.

Garfunkel, Z., C. A. Anderson, and G. Schubert (1986), Mantle circulation and the lateral migration of subducted slabs, J. Geophys. Res., 91, 7205-7223, doi:10.1029/JB091iB07p07205.

Greve, S. M., M. K. Savage, and S. D. Hofmann (2008), Strong variations in seismic anisotropy across the Hikurangi subduction zone, North Island, New Zealand, Tectonophysics, 462, 7-21, doi:10.1016/j.tecto. 2007.07.011.

Gripp, A. E., and R. G. Gordon (2002), Young tracks of hotspots and current plate velocities, Geophys. J. Int., 150, 321-361, doi:10.1046/ j.1365-246X.2002.01627.x

Growdon, M. A., G. L. Pavlis, F. Niu, F. L. Vernon, and H. Rendon (2009), Constraints on mantle flow at the Caribbean-South American plate boundary inferred from shear wave splitting, J. Geophys. Res., 114 B02303, doi:10.1029/2008JB005887.

Healy, D., S. M. Reddy, N. E. Timms, E. M. Gray, and A. Vitale Brovarone (2009), Trench-parallel fast axes of seismic anisotropy due to fluid-filled cracks in subducting slabs, Earth Planet. Sci. Lett., 283, 75-86, doi:10.1016/j.epsl.2009.03.037.

Herrstrom, E. A., M. K. Reagan, and J. D. Morris (1995), Variations in lava composition associated with flow of asthenosphere beneath southern Central America, Geology, 23, 617-620, doi:10.1130/0091-7613(1995) $023<0617$ :VILCAW $>2.3$.CO 2 .

Hoernle, K., et al. (2008), Arc-parallel flow in the mantle wedge beneath Costa Rica and Nicaragua, Nature, 451, 1094-1097, doi:10.1038/ nature 06550

Holtzman, B. K., D. L. Kohlstedt, M. E. Zimmerman, F. Heidelbach, T. Hiraga, and J. Hustoft (2003), Melt segregation and strain partitioning: Implications for seismic anisotropy and mantle flow, Science, 301, 1227-1230, doi:10.1126/science.1087132.

Honda, S. (2009), Numerical simulations of mantle flow around slab edges, Earth Planet. Sci. Lett., 277, 112-122, doi:10.1016/j.epsl.2008.10.003.

Husen, S., R. Quintero, E. Kissling, and B. Hacker (2003), Subductionzone structure and magmatic processes beneath Costa Rica constrained by local earthquake tomography and petrological modeling, Geophys. J. Int., 155, 11-32, doi:10.1046/j.1365-246X.2003.01984.x.

Ismaill, W. B., and D. Mainprice (1998), An olivine fabric database: An overview of upper mantle fabrics and anisotropy, Tectonophysics, 296, 145-157, doi:10.1016/S0040-1951(98)00141-3.

Jacobsen, S. D., F. Jiang, Z. Mao, T. S. Duffy, J. R. Smyth, C. M. Holl, and D. J. Frost (2008), Effects of hydration on the elastic properties of olivine, Geophys. Res. Lett., 35, L14303, doi:10.1029/2008GL034398.

Johnston, S. T., and D. J. Thorkelson (1997), Cocos-Nazca slab window beneath Central America, Earth Planet. Sci. Lett., 146, 465-474, doi:10.1016/S0012-821X(96)00242-7.

Jung, H., and S.-i. Karato (2001), Water-induced fabric transitions in olivine, Science, 293, 1460-1463, doi:10.1126/science.1062235.

Jung, H., I. Katayama, Z. Jiang, T. Hiraga, and S. Karato (2006), Effect of water and stress on the lattice-preferred orientation of olivine, Tectonophysics, 421, 1-22, doi:10.1016/j.tecto.2006.02.011.

Katayama, I., and S.-i. Karato (2006), Effect of temperature on the B- to C-type olivine fabric transition and implication for flow pattern in subduction zones, Phys. Earth Planet. Inter., 157, 33-45, doi:10.1016/j. pepi.2006.03.005

Kennett, B. L. N. (1991), The removal of free-surface interactions from 3-component seismograms, Geophys. J. Int., 104, 153-154, doi:10.1111/j.1365-246X.1991.tb02501.x.
Kennett, B. L. N., E. R. Engdahl, and R. Buland (1995), Constraints on seismic velocities in the Earth from travel times, Geophys. J. Int., 122, 108-124, doi:10.1111/j.1365-246X.1995.tb03540.x.

Kincaid, C., and R. W. Griffiths (2003), Laboratory models of the thermal evolution of the mantle during rollback subduction, Nature, 425, 58-62, doi:10.1038/nature01923.

Kincaid, C., and R. W. Griffiths (2004), Variability in flow and temperatures within mantle subduction zones, Geochem. Geophys. Geosyst., 5 , Q06002, doi:10.1029/2003GC000666.

Kneller, E. A., and P. E. van Keken (2008), Effect of three-dimensional slab geometry on deformation in the mantle wedge: Implications for shear wave anisotropy, Geochem. Geophys. Geosyst., 9, Q01003, doi:10.1029/2007GC001677.

Kneller, E. A., P. E. van Keken, S.-i. Karato, and J. Park (2005), B-type olivine fabric in the mantle wedge: Insights from high-resolution non-Newtonian subduction zone models, Earth Planet. Sci. Lett., 237, 781-797, doi:10.1016/j.eps1.2005.06.049.

Levin, V., D. Droznin, J. Park, and E. Gordeev (2004), Detailed mapping of seismic anisotropy with local shear waves in southeastern Kamchatka, Geophys. J. Int., 158, 1009-1023, doi:10.1111/j.1365-246X.2004. 02352.x.

Li, C., R. D. van der Hilst, E. R. Engdahl, and S. Burdick (2008), A new global model for P wave speed variations in Earth's mantle, Geochem Geophys. Geosyst., 9, Q05018, doi:10.1029/2007GC001806.

Long, M. (2009), Complex anisotropy in D" beneath the eastern Pacific from SKS-SKKS splitting discrepancies, Earth Planet. Sci. Lett., 283, 181-189, doi:10.1016/j.epsl.2009.04.019.

Long, M. D., and P. G. Silver (2008), The subduction zone flow field from seismic anisotropy: A global view, Science, 319, 315-318, doi:10.1126/ science. 1150809

Long, M. D., and P. G. Silver (2009), Mantle flow in subduction systems: The subslab flow field and implications for mantle dynamics, J. Geophys. Res., 114, B10312, doi:10.1029/2008JB006200.

Long, M. D., and R. D. van der Hilst (2005), Upper mantle anisotropy beneath Japan from shear wave splitting, Phys. Earth Planet. Inter. 151, 206-222, doi:10.1016/j.pepi.2005.03.003.

Mainprice, D., and P. G. Silver (1993), Interpretation of SKS-waves using samples from the subcontinental lithosphere, Phys. Earth Planet. Inter. 78, 257-280, doi:10.1016/0031-9201(93)90160-B.

Mainprice, D., G. Barruol, and W. Ben Ismail (2000), The seismic anisotropy of the Earth's mantle: From single crystal to polycrystal, in Earth's Deep Interior: Mineral Physics and Tomography From the Atomic to the Global Scale, Geophys. Monogr. Ser., vol. 117, edited by S.-i. Karato et al., pp. 237-264, AGU, Washington, D. C.

Müller, C., B. Bayer, A. Eckstaller, and H. Miller (2008), Mantle flow in the South Sandwich subduction environment from source-side shear wave splitting, Geophys. Res. Lett., 35, L03301, doi:10.1029/2007GL032411.

Niu, F., and A. M. Perez (2004), Seismic anisotropy in the lower mantle: A comparison of waveform splitting of SKS and SKKS, Geophys. Res. Lett. 31, L24612, doi:10.1029/2004GL021196.

O'Neill, C., D. Müller, and B. Steinberger (2005), On the uncertainties in hot spot reconstructions and the significance of moving hot spot reference frames, Geochem. Geophys. Geosyst., 6, Q04003, doi:10.1029/ 2004GC000784.

Piñero-Feliciangeli, L. T., and J.-M. Kendall (2008), Sub-slab mantle flow parallel to the Caribbean plate boundaries: Inferences from $S K S$ splitting, Tectonophysics, 462, 22-34, doi:10.1016/j.tecto.2008.01.022.

Pozgay, S. H., D. A. Wiens, J. A. Conder, H. Shiobara, and H. Sugioka (2007), Complex mantle flow in the Mariana subduction system: Evidence from shear wave splitting, Geophys. J. Int., 170, 371-386, doi:10.1111/j.1365-246X.2007.03433.x.

Protti, M., F. Gundel, and K. McNally (1994), The geometry of the WadditiBenioff zone under southern Central America and its tectonic significance: Results from a high resolution local seismographic network, Phys. Earth Planet. Inter., 84, 271-287, doi:10.1016/0031-9201(94)90046-9.

Ren, Y., E. Stutzmann, R. D. van der Hilst, and J. Besse (2007), Understanding seismic heterogeneities in the lower mantle beneath the Americas from seismic tomography and plate tectonic history, J. Geophys. Res., 112, B01302, doi:10.1029/2005JB004154

Restivo, A., and G. Helffrich (2006), Core-mantle boundary structure investigated using SKS and SKKS polarization anomalies, Geophys. J. Int., 165, 288-302, doi:10.1111/j.1365-246X.2006.02901.x.

Ritsema, J., H. J. van Heijst, and J. H. Woodhouse (2004), Global transition zone tomography, J. Geophys. Res., 109, B02302, doi:10.1029/ 2003JB002610.

Russo, R. M., and P. G. Silver (1994), Trench-parallel flow beneath the Nazca Plate from seismic anisotropy, Science, 263, 1105-1111, doi:10.1126/science.263.5150.1105. 
Russo, R. M., P. G. Silver, M. Franke, W. B. Ambeh, and D. E. James (1996), Shear-wave splitting in northeast Venezuela, Trinidad, and the eastern Caribbean, Phys. Earth Planet. Inter., 95, 251-275, doi:10.1016/ 0031-9201(95)03128-6.

Sallarès, V., J. J. Dañobeitia, and E. R. Flueh (2000), Seismic tomography with local earthquakes in Costa Rica, Tectonophysics, 329, 61-78, doi:10.1016/S0040-1951(00)00188-8.

Savage, M. K. (1999), Seismic anisotropy and mantle deformation: What have we learned from shear wave splitting, Rev. Geophys., 37, 65-106, doi:10.1029/98RG02075.

Schellart, W. P., J. Freeman, D. R. Stegman, L. Moresi, and D. May (2007), Evolution and diversity of subduction zones controlled by slab width, Nature, 446, 308-311, doi:10.1038/nature05615.

Schellart, W. P., D. R. Stegman, and J. Freeman (2008), Global trench migration velocities and slab migration induced upper mantle volume fluxes: Constraints to an Earth reference frame based on minimizing viscous dissipation, Earth Sci. Rev., 88, 118-144, doi:10.1016/j.earscirev. 2008.01 .005$.

Silver, P. G., and W. W. Chan (1991), Shear wave splitting and subcontinental mantle deformation, J. Geophys. Res., 96, 16,429-16,454 doi:10.1029/91JB00899.

Smith, G. P., D. A. Wiens, K. M. Fischer, L. M. Dorman, S. C. Webb, and J. H. Hildebrand (2001), A complex pattern of flow in the Lau backarc, Science, 292, 713-716, doi:10.1126/science.1058763.
Syracuse, E. M., and G. A. Abers (2006), Global compilation of variations in slab depth beneath arc volcanoes and implications, Geochem. Geophys. Geosyst., 7, Q05017, doi:10.1029/2005GC001045.

Syracuse, E. M., G. A. Abers, K. M. Fischer, L. MacKenzie, C. Rychert, J. M. Protti, V. Gonzalez, and W. Strauch (2008), Seismic tomography and earthquake locations in the Nicaraguan and Costa Rican upper mantle, Geochem. Geophys. Geosyst., 9, Q07S08, doi:10.1029/ 2008 GC001963.

Weinberg, R. F. (1992), Neotectonic development of western Nicaragua, Tectonics, 11, 1010-1017, doi:10.1029/92TC00859.

Zhang, S., and S.-i. Karato (1995), Lattice preferred orientation of olivine aggregates deformed in simple shear, Nature, 375, 774-777, doi:10.1038 $375774 \mathrm{a} 0$.

G. A. Abers, Lamont-Doherty Earth Observatory, Earth Institute at Columbia University, Palisades, NY 10964, USA

D. L. Abt, ExxonMobil Exploration Company, 233 Benmar Dr., Houston, TX 77060, USA. (david.1.abt@exxonmobil.com)

K. M. Fischer, Department of Geological Sciences, Brown University, Providence, RI 02912, USA.

V. González and M. Protti, Observatorio Vulcanológico y Sismológico de Costa Rica, Universidad Nacional, Apdo. 86-3000 Heredia, Costa Rica.

W. Strauch, Instituto Nicaragüense de Estudios Territoriales, Apdo. 2110 Managua, Nicaragua 